\title{
Comparison of gene expression profiles and related pathways in chronic thromboembolic pulmonary hypertension
}

\author{
SONG GU* ${ }^{*}$ PIXIONG SU* , JUN YAN, XITAO ZHANG, XIANGGUANG AN, JIE GAO, RUI XIN and YAN LIU \\ Department of Cardiac Surgery, Beijing Chao-Yang Hospital, Capital Medical University, Beijing 100020, P.R. China
}

Received August 22, 2013; Accepted December 3, 2013

DOI: $10.3892 / \mathrm{ijmm} .2013 .1582$

\begin{abstract}
Chronic thromboembolic pulmonary hypertension (CTEPH) is one of the main causes of severe pulmonary hypertension. However, despite treatment (pulmonary endarterectomy), in approximately $15-20 \%$ of patients, pulmonary vascular resistance and pulmonary arterial pressure continue to increase. To date, little is known about the changes that occur in gene expression in CTEPH. The identification of genes associated with CTEPH may provide insight into the pathogenesis of CTEPH and may aid in diagnosis and treatment. In this study, we analyzed the gene expresion profiles of pulmonary artery endothelial cells from 5 patients with CTEPH and 5 healthy controls using oligonucleotide microarrays. Bioinformatics analyses using the Gene Ontology (GO) and KEGG databases were carried out to identify the genes and pathways specifically associated with CTEPH. Signal transduction networks were established to identify the core genes regulating the progression of CTEPH. A number of genes were found to be differentially expressed in the pulmonary artery endothelial cells from patients with CTEPH. In total, $412 \mathrm{GO}$ terms and 113 pathways were found to be associated with our list of genes. All differential gene interactions in the Signal-Net network were analyzed. JAK3, GNA15, MAPK13, ARRB2 and F2R were the most significantly altered. Bioinformatics analysis may help gather and analyze large amounts of data in microarrays by means of rigorous experimental planning, scientific statistical analysis and the collection of complete data. In this study, a novel differential gene expression pattern was constructed. However, further studies are required to identify novel targets for the diagnosis and treatment of CTEPH.
\end{abstract}

\section{Introduction}

Chronic thromboembolic pulmonary hypertension (CTEPH) is one of the main causes of severe pulmonary hypertension. CTEPH is characterized by the presence of unresolved throm-

Correspondence to: Professor Yan Liu, Department of Cardiac Surgery, Beijing Chao-Yang Hospital, Capital Medical University, 8th Workers Stadium South Road, Beijing 100020, P.R. China

E-mail: liuyanok2@hotmail.com

*Contributed equally

Key words: chronic thromboembolic pulmonary hypertension, gene, microarray, Gene Ontology, signaling pathway boemboli associated with fibrous stenosis in the proximal pulmonary arteries. Diagnosis is usually made in the advanced stages of the disease when pulmonary vascular resistance (PVR) has increased by 5- to 10-fold. This increase in PVR resistance results in pulmonary hypertension and progressive right heart failure. It may be caused by a single or recurrent pulmonary embolism and/or the local formation of thrombi. The proximal location of pulmonary artery obliteration is the main feature observed in patients with CTEPH that differs from pulmonary arterial hypertension (PAH) (1).

Depending on the localization and extent of proximal thrombotic material, a pulmonary endarterectomy (PEA) may be necessary (2). Approximately half of the pulmonary blood flow dynamics can return to normal levels following PEA. However, in approximately $15-20 \%$ of patients, PVR and pulmonary arterial pressure (PAP) continue to rise, thus increasing the mortality rate by up to $4-5 \%$ (3). It has been suggested that the reason for the development of the persistent occlusion of the pulmonary artery is a misguided thrombus resolution triggered by infection (4), inflammation (5), autoimmunity, malignancy (6) and/or endothelial dysfunction due to a high presence of phospholipid antibodies and lupus anticoagulants $(7,8)$ rather than prothrombotic factors.

A number of factors, such as C-reactive protein (CRP) (9), endothelin-1 and von Willebrand factor (10) may participate in the pathophysiology of pulmonary hypertension. However, there are hundreds of implicated genomic loci with heterogeneous functions. As a result, there is difficulty in understanding the mechanisms by which this diverse genetic susceptibility translates to a common clinical phenotype. The advent of genome-wide technologies, such as gene expression microarray, has made it possible to achieve a comprehensive view of the alterations in gene expression occurring in CTEPH. In the present study, we used bioinformatics to analyze the differences in gene expression between CTEPH and normal tissue. The different Gene Ontology (GO) terms and pathways revealed the most important mechanisms and candidate genes involved in the development of CTEPH; our data may aid in the development of more individualized treatment regimens according to the genetic characteristics of individual patients.

\section{Patients and methods}

Patients. Five consecutive patients with CTEPH were enrolled in this study from the Beijing Chao-Yang Hospital, Capital Medical University, Beijing, China between June 2012 and February 2013. The study was approved by the relevant ethics commitee and all 
patients provided written consent to participate in this study. All patients were examined using lung ventilation and perfusion scans, right-heart catheterization and pulmonary angiography to confirm the diagnosis. Patients with CTEPH were defined as those having a mean pulmonary arterial pressure (mPAP) of $\geq 25 \mathrm{mmHg}$ with normal wedge pressure $(\leq 12 \mathrm{mmHg}$ ) who had dyspnea on exertion during a period of $>6$ months on effective anticoagulation. In addition, lung perfusion scans were performed to demonstrate a segmental or larger defect concomitant with a normal ventilation scan $(11,12)$. Finally, chronic thromboembolic findings were confirmed on pulmonary angiography (13). Five healthy controls (donors for lung transplants) were also included.

Microarray analysis. For Affymetrix microarray profiling, total RNA of CTEPH and normal tissues was isolated using TRIzol reagent (Invitrogen, Burlington, ON, Canada) and purified using the RNeasy Mini kit (Qiagen, Hilden, Germany), including a DNase digestion treatment. RNA concentrations were determined by absorbance (A) at $260 \mathrm{~nm}$ and quality control standards were A260/A280 = 1.8-2.1, using a NanoDrop 2000 spectrophotometer (Thermo Scientific, Wilmington, DE, USA).

cDNA of pulmonary artery endothelial cells from patients with CTEPH or the normal controls was hybridized to Human Gene 2.0 ST GeneChip ${ }^{\circledR}$ arrays (Affymetrix, Inc., Santa Clara, CA, USA) according to the manufacturer's instructions. Affymetrix ${ }^{\circledR}$ Expression Console Software (version 1.2.1) was used for microarray analysis. Raw data (CEL files) were normalized at the transcript level using the robust multiaverage method (RMA workflow). The median summarization of transcript expressions was calculated. Gene-level data was then filtered to include only those probe sets that are in the 'core' metaprobe list, which represent RefSeq genes.

Analysis of differential gene expression. The RVM t-test was applied to filter the differentially expressed genes for the control and experimental group, as the RVM t-test can raise degrees of freedom effectively in the cases of small samples. After the analysis of differentially expressed genes and false discovery rate (FDR) analysis, we selected the differentially expressed genes according to the $\mathrm{P}$-value threshold. A value of $\mathrm{P}<0.05$ was considered to indicate a statistically significant difference, as previously described (14-16). The data of differentially expressed genes were subjected to unsupervised hierarchical clustering (Cluster 3.0) and TreeView analysis (Stanford University, Stanford, CA, USA).

$G O$ analysis. GO analysis was applied to determine the main functions of the differential expression genes according to the GO database, which is the key functional classification of NCBI, which organizes genes into hierarchical categories and identifies the gene regulatory network on the basis of biological process and molecular function $(17,18)$.

Specifically, a two-sided Fisher's exact test and $\chi^{2}$ test were used to classify the GO categories, and the FDR (19) was calculated to correct the P-value; the smaller the FDR, the smaller the error in judging the P-value. The FDR was defined as:

$$
F D R=1-\frac{N_{k}}{T}
$$

where $N_{k}$ refers to the number of Fisher's test P-values less than $\chi^{2}$ test P-values. We computed P-values for the GO terms of all the differentially expressed genes. Enrichment analysis provides a measure of the significance of the function: as the enrichment increases, the corresponding function is more specific, which helps us to find those GO terms with a more concrete functional description in the experiment. Within the significance category, the enrichment $\operatorname{Re}$ was given by $\operatorname{Re}=\left(n_{f} / n\right) /\left(N_{f} / N\right)$, where $n_{f}$ is the number of flagged genes within the particular category, $n$ is the total number of genes within the same category, $N_{f}$ is the number of flagged genes in the entire microarray, and $N$ is the total number of genes in the microarray, as previously described (20).

GO-map. GO-map analysis is the interaction network of the significant GO terms of the differentially expressed genes, and was carried out to integrate the associations between these GO terms by outlining the interactions of related GO terms and summarizing the functional interactions of the differentially expressed genes in diseases $(18,20)$.

Pathway analysis. Pathway analysis was used to identify the common pathways associated with the differentially expressed genes according to the KEGG, BioCarta and Reatome databases. We used the Fisher's exact test and $\chi^{2}$ test to identify the significant pathways, and the threshold of significance was defined by a P-value and FDR. The enrichment Re was calculated with the equation described above, as previously described (21-23).

Path-Net. Path-Net is the interaction network of the most common pathways associated with the differentially expressed genes, and was built according to the interaction among pathways of the KEGG database to determine the interactions among the significant pathways directly and systemically. It identified the common pathways associated with the differentially expressed genes, as well as the mechanisms behind the activation of a certain pathway (22).

Signal-Net analysis. Using java that allows users to build and analyze molecular networks, network maps were constructed. For instance, if there is confirmative evidence that two genes interact with each other, an interaction edge is assigned between the two genes. The considered evidence is the source of the interaction database from KEGG. Networks are stored and presented as graphs, where nodes are mainly genes (protein, compound, etc.) and edges represent relation types between the nodes, e.g., activation or phosphorylation. The graph nature of Networks peaked our interest to investigate them with powerful tools implemented in R.

In order to investigate the global network, we computationally identified the most important nodes. To this end, we determined the connectivity (also known as the degree) defined as the sum of connection strengths with the other network genes:

$$
\mathrm{K}_{i}=\sum_{u \neq i} a_{u i}
$$

In gene networks, the connectivity measures how well a gene correlates with all other network genes. For a gene in the network, the number of source genes of a gene is called the 
Table I. Clinical characteristics of the patients in this study.

\begin{tabular}{lcccccc}
\hline Sample & No. & $\begin{array}{c}\text { Age (years) } \\
\text { mean } \pm \text { SD }\end{array}$ & Gender (M/F) & $\begin{array}{c}\text { mPAP (mmHg) } \\
\text { median (range) }\end{array}$ & $\begin{array}{c}\text { PVR } \\
\left(\text { dyne}^{*} \cdot \mathrm{cm}^{-5}\right)\end{array}$ \\
\hline Healthy controls & 5 & $35.3 \pm 10.6$ & $2 / 3$ & - & - \\
CTEPH patients & 5 & $38.2 \pm 14.7$ & $2 / 3$ & $55(33-78)$ & 1075.4 & 454.7 \\
\hline
\end{tabular}

mPAP, mean pulmonary arterial pressure; PVR, pulmonary vascular resistance; CTEPH, chronic thromboembolic pulmonary hypertension; 6 WMT, 6-min walk test.

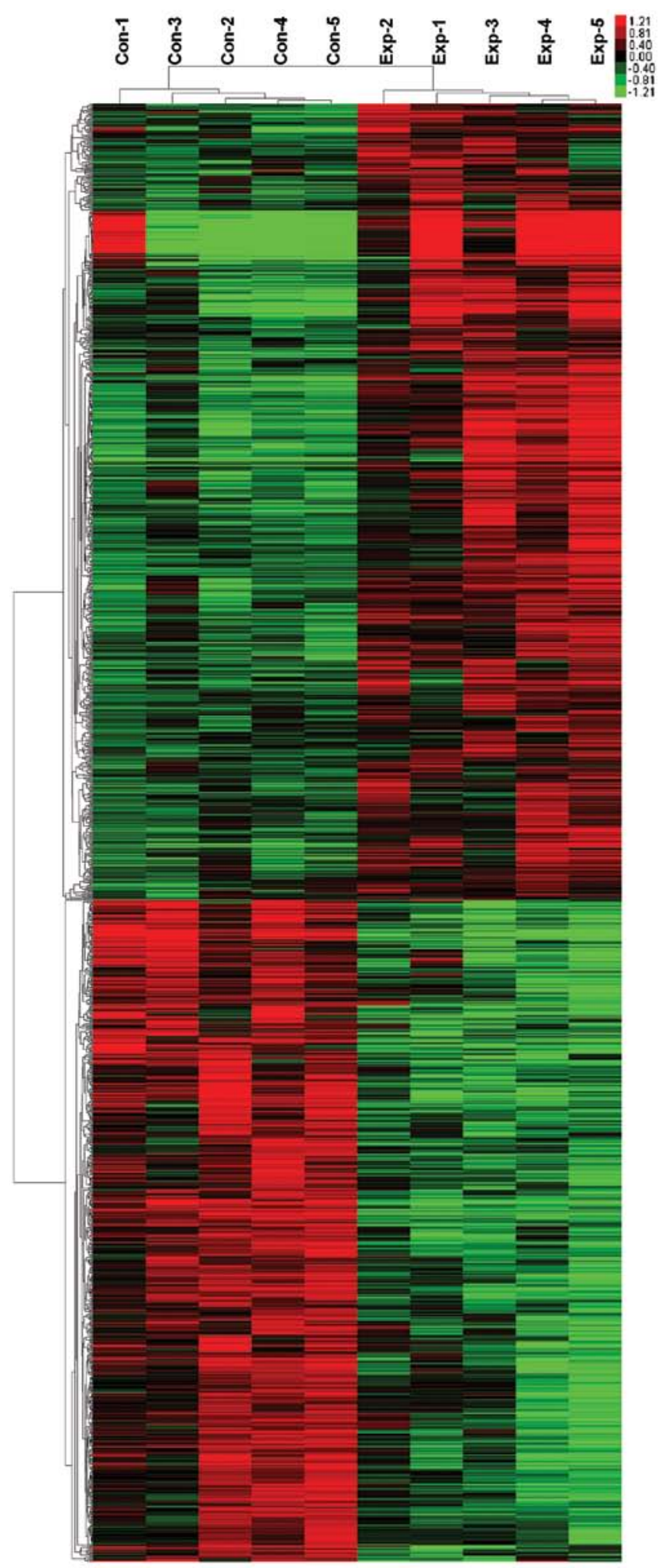

Table II. Most significantly upregulated genes.

\begin{tabular}{lrrrr}
\hline $\begin{array}{l}\text { Gene } \\
\text { symbol }\end{array}$ & P-value & $\begin{array}{c}\text { Geom mean } \\
\text { of intensities } \\
\text { in CTEPH } \\
\text { group }\end{array}$ & $\begin{array}{c}\text { Geom mean } \\
\text { in hensities } \\
\text { in holthy } \\
\text { controls }\end{array}$ & $\begin{array}{c}\text { Fold- } \\
\text { change }\end{array}$ \\
\hline PTGS2 & $1.25 \mathrm{E}-05$ & 155.56 & 38.18 & 4.07 \\
TBX15 & $2.35 \mathrm{E}-05$ & 95.07 & 23.66 & 4.02 \\
FMO3 & $3.00 \mathrm{E}-05$ & 120.33 & 16.06 & 7.49 \\
LRRC32 & $3.03 \mathrm{E}-05$ & 445.65 & 151.99 & 2.93 \\
FAM100B & $3.87 \mathrm{E}-05$ & 181.47 & 92.94 & 1.95 \\
NEIL3 & $4.62 \mathrm{E}-05$ & 16.92 & 10 & 1.69 \\
LOC100507286 & $8.50 \mathrm{E}-05$ & 33.52 & 10.1 & 3.32 \\
LY75 & $9.46 \mathrm{E}-05$ & 166.81 & 70.72 & 2.36 \\
ITIH3 & $1.27 \mathrm{E}-04$ & 79.24 & 15.24 & 5.2 \\
TRPV2 & $1.29 \mathrm{E}-04$ & 45.02 & 24.8 & 1.82 \\
\hline
\end{tabular}

Table III. Most significantly downregulated genes.

\begin{tabular}{lcccc}
\hline $\begin{array}{l}\text { Gene } \\
\text { symbol }\end{array}$ & $\begin{array}{r}\text { P-value } \\
\text { intensities in } \\
\text { CTEPH group }\end{array}$ & $\begin{array}{c}\text { Geom mean of } \\
\text { intensities in } \\
\text { healthy controls }\end{array}$ & $\begin{array}{c}\text { Fold- } \\
\text { change }\end{array}$ \\
\hline CHRDL1 & $5.00 \mathrm{E}-07$ & 11.14 & 344.38 & 0.032 \\
FREM1 & $1.00 \mathrm{E}-06$ & 13.58 & 69.85 & 0.19 \\
BNC2 & $1.20 \mathrm{E}-06$ & 33.6 & 92.91 & 0.36 \\
ACADL & $1.30 \mathrm{E}-06$ & 13.98 & 72.87 & 0.19 \\
UNC13C & $3.10 \mathrm{E}-06$ & 10 & 27.03 & 0.37 \\
NCAM1 & $3.20 \mathrm{E}-06$ & 17.13 & 75.75 & 0.23 \\
PRUNE2 & $3.30 \mathrm{E}-06$ & 221.46 & 706.72 & 0.31 \\
KLHDC5 & $4.50 \mathrm{E}-06$ & 25.88 & 57.87 & 0.45 \\
FERMT2 & $7.40 \mathrm{E}-06$ & 222.13 & 409.8 & 0.54 \\
FAM198A & $7.60 \mathrm{E}-06$ & 24.03 & 48.54 & 0.5 \\
\hline
\end{tabular}

Figure 1. Unsupervised classification of chronic thromboembolic pulmonary hypertension (CTEPH) and healthy control samples based on gene expression profiling. Classification of 10 pulmonary artery endothelial cell samples using the differentially expressed 2098-probe sets. Expression data are depicted as a data matrix where each row represents a gene and each column represents a sample. Expression levels are depicted according to the color scale shown at the top. Red and green indicate expression levels above and below the median, respectively. The magnitude of deviation from the median is represented by the color saturation. 
Table IV. GO items and enrichment scores.

GO name

Enrichment score

T cell selection

34.56136364

$\mathrm{T}$ cell activation via $\mathrm{T}$ cell receptor contact with antigen bound to MHC molecule on antigen

34.56136364

presenting cell

Cell surface pattern recognition receptor signaling pathway

34.56136364

Dicarboxylic acid transport

34.56136364

Cyclooxygenase pathway

34.56136364

Positive regulation of mast cell activation

34.56136364

Regulatory $\mathrm{T}$ cell differentiation

34.56136364

Positive regulation of interleukin-10 biosynthetic process

34.56136364

Positive regulation of interleukin-4 biosynthetic process

34.56136364

RNA destabilization

34.56136364

Negative regulation of calcium-mediated signaling

34.56136364

Regulation of cytokine-mediated signaling pathway

23.04090909

Positive regulation of immunoglobulin mediated immune response

23.04090909

Protein deglycosylation

23.04090909

Detection of biotic stimulus

23.04090909

Regulation of smooth muscle cell migration

23.04090909

Viral envelope fusion with host membrane

23.04090909

Lipoxygenase pathway

23.04090909

Response to vitamin B3

23.04090909

Regulation of NF-kappaB import into nucleus

23.04090909

Positive regulation of granulocyte macrophage colony-stimulating factor biosynthetic process

23.04090909

Regulation of cellular component movement

23.04090909

Adhesion to symbiont

23.04090909

Nucleotide-binding oligomerization domain containing 1 signaling pathway

23.04090909

Connective tissue replacement involved in inflammatory response wound healing

20.73681818

Response to peptidoglycan

20.73681818

Regulation of B cell differentiation

20.73681818

Regulation of $\mathrm{T}$ cell activation

20.73681818

Nucleotide-binding oligomerization domain containing 2 signaling pathway

20.73681818

Positive regulation of alpha-beta $\mathrm{T}$ cell proliferation

18.85165289

Chronic inflammatory response

17.28068182

Regulation of $\mathrm{T}$ cell differentiation

17.28068182

Platelet activating factor biosynthetic process

17.28068182

Tyrosine phosphorylation of STAT protein

17.28068182

Pyridine nucleotide biosynthetic process

17.28068182

Regulation of cholesterol transport

17.28068182

Negative regulation of collagen biosynthetic process

17.28068182

Very-low-density lipoprotein particle clearance

17.28068182

Positive regulation of interferon-alpha biosynthetic process

17.28068182

Negative regulation of follicle-stimulating hormone secretion

17.28068182

Antigen processing and presentation of exogenous peptide antigen via MHC class II

14.81201299

Positive regulation of interleukin-2 biosynthetic process

14.23114973

Negative regulation of signal transduction

14.13873967

Chronological cell aging

13.82454545

Membrane raft polarization

13.82454545

Response to molecule of fungal origin

13.82454545

Leukotriene production involved in inflammatory response

13.82454545

Macrophage derived foam cell differentiation 
Table IV. Continued.

GO name

Enrichment score

Membrane to membrane docking

13.82454545

Negative regulation of granulocyte differentiation

13.82454545

Tie receptor signaling pathway

13.82454545

Positive regulation of hair follicle development

13.82454545

Positive regulation of chemokine production

12.96051136

Positive regulation of macrophage chemotaxis

12.96051136

Lymphocyte chemotaxis

12.96051136

Negative thymic T cell selection

11.52045455

Negative regulation of blood vessel endothelial cell migration

11.52045455

Positive thymic T cell selection

11.52045455

Positive regulation of humoral immune response mediated by circulating immunoglobulin

11.52045455

Positive regulation of cytokine-mediated signaling pathway

11.52045455

Positive regulation of natural killer cell mediated cytotoxicity directed against tumor cell target

11.52045455

Negative regulation of lipid storage

11.52045455

Death

11.52045455

Cellular response to nutrient

11.52045455

Positive regulation of actin filament bundle assembly

11.52045455

Very-low-density lipoprotein particle assembly

11.52045455

Positive regulation of T-helper 1 cell differentiation

11.52045455

Myoblast proliferation

11.52045455

Negative regulation of focal adhesion assembly

11.52045455

T-helper 1 type immune response

10.63426573

Enzyme linked receptor protein signaling pathway

10.36840909

Negative regulation of plasminogen activation

10.36840909

Leukocyte tethering or rolling

10.36840909

Cell recognition

9.874675325

Positive regulation of necrotic cell death

9.874675325

Positive regulation of $\mathrm{T}$ cell receptor signaling pathway

9.874675325

Angiogenesis involved in wound healing

9.874675325

Placenta blood vessel development

9.874675325

Prostaglandin biosynthetic process

9.600378788

Immunoglobulin mediated immune response

9.600378788

Defense response to protozoan

9.425826446

Positive regulation of cytokine production

9.216363636

Leukocyte cell-cell adhesion

9.095095694

RNA catabolic process

9.095095694

I-kappaB kinase/NF-kappaB cascade

8.84127907

Cellular defense response

8.640340909

Microglial cell activation involved in immune response

8.640340909

Initiation of viral infection

8.640340909

Positive regulation of interferon-gamma biosynthetic process

8.640340909

Respiratory burst

Negative regulation of T cell-mediated cytotoxicity

$\mathrm{N}$-glycan processing

Chylomicron remnant clearance

Regulation of mast cell degranulation

Positive regulation of interleukin- 8 biosynthetic process

Negative regulation of nitric-oxide synthase activity

Maternal process involved in parturition 
Table IV. Continued.

GO name

Enrichment score

Platelet dense granule organization

8.640340909

Branching involved in embryonic placenta morphogenesis

8.640340909

Positive regulation of calcium-mediated signaling

8.064318182

Humoral immune response

8.023173701

Chemotaxis

8.018236364

Response to reactive oxygen species

7.975699301

Defense response

7.68030303

Positive regulation of $\mathrm{T}$ cell proliferation

7.513339921

Negative regulation of interleukin-12 production

7.406006494

Skeletal muscle tissue regeneration

7.406006494

Positive regulation of innate immune response

7.406006494

Lymph node development

7.406006494

Cellular response to lipoteichoic acid

7.406006494

Positive regulation of interleukin-1 beta secretion

7.276076555

Response to exogenous dsRNA

6.912272727

Decidualization

6.912272727

Regulation of peptidyl-tyrosine phosphorylation

6.912272727

Germinal center formation

6.912272727

Natural killer cell activation

6.912272727

Positive regulation of interleukin-17 production

6.912272727

Defense response to Gram-positive bacterium

6.646416084

Hemopoietic progenitor cell differentiation

6.583116883

JAK-STAT cascade

6.538636364

Acute inflammatory response

6.480255682

Cellular copper ion homeostasis

6.480255682

Positive regulation of $\mathrm{B}$ cell differentiation

6.480255682

Response to gamma radiation

6.283884298

Neutrophil chemotaxis

6.283884298

$\mathrm{T}$ cell activation

6.232377049

Metabolic process

6.099064171

$\mathrm{T}$ cell differentiation

6.099064171

Sprouting angiogenesis

6.099064171

Positive regulation of tumor necrosis factor biosynthetic process

6.099064171

Positive regulation of survival gene product expression

6.099064171

Induction of positive chemotaxis

6.099064171

Response to progesterone stimulus

6.048238636

Negative regulation of endothelial cell proliferation

5.958855799

Response to bacterium

5.760227273

Response to interferon-gamma

5.760227273

Induction of apoptosis via death domain receptors

5.760227273

Negative regulation of blood coagulation

5.760227273

Positive regulation of smooth muscle contraction

5.760227273

Inflammatory response

5.541909621

Negative regulation of growth of symbiont in host

5.529818182

Oligosaccharide metabolic process

5.457057416

Cellular component movement

5.368755516

Negative regulation of cell adhesion

5.236570248

Mesoderm development

5.236570248

Copper ion transport 
Table IV. Continued.

GO name

Positive regulation of blood coagulation

Negative regulation of phosphorylation

Positive regulation of NF-kappaB import into nucleus

Positive regulation of blood vessel endothelial cell migration

Nitrogen compound metabolic process

Positive regulation vascular endothelial growth factor production

Positive regulation of interleukin- 8 production

Response to cytokine stimulus

Positive regulation of interleukin-6 production

Response to inorganic substance

Response to vitamin D

Amino acid transport

B cell proliferation

Positive regulation of erythrocyte differentiation

Response to interleukin-1

Positive regulation of interferon-gamma production

Lipopolysaccharide-mediated signaling pathway

Positive regulation of $\mathrm{B}$ cell proliferation

Positive regulation of smooth muscle cell proliferation

Negative regulation of $\mathrm{T}$ cell proliferation

Response to virus

Ion transport

Protein import into nucleus, translocation

Negative regulation of NF-kappaB transcription factor activity

$B$ cell differentiation

Heterophilic cell-cell adhesion

Response to mechanical stimulus

Immune response

Positive regulation of tumor necrosis factor production

Cholesterol efflux

$\mathrm{B}$ cell receptor signaling pathway

Induction of apoptosis

Phagocytosis

Positive regulation of nitric oxide biosynthetic process

Positive regulation of NF-kappaB transcription factor activity

Regulation of cell adhesion

Rho protein signal transduction

Positive regulation of inflammatory response

Anti-apoptosis

Response to stimulus

Response to peptide hormone stimulus

Protein complex assembly

Cellular calcium ion homeostasis

Elevation of cytosolic calcium ion concentration

Positive regulation of angiogenesis

Response to wounding

Cell-cell signaling

Induction of apoptosis by extracellular signals

Defense response to virus
Enrichment score

5.184204545

5.184204545

5.184204545

5.184204545

4.937337662

4.937337662

4.937337662

4.883670949

4.838590909

4.767084639

4.767084639

4.712913223

4.712913223

4.712913223

4.670454545

4.564708405

4.430944056

4.412088975

4.388744589

4.320170455

4.291934046

4.203409091

4.189256198

4.10050077

4.066042781

4.066042781

3.879336735

3.769560495

3.75666996

3.736363636

3.736363636

3.697923681

3.456136364

3.388368984

3.352968114

3.344648094

3.323208042

3.323208042

3.318806442

3.291558442

3.200126263

3.19027972

3.174002783

3.141942149

3.110522727

3.049532086

3.034012838

3.005335968

3.005335968 
Table IV. Continued.

GO name

Enrichment score

Response to lipopolysaccharide

2.948362775

Positive regulation of peptidyl-tyrosine phosphorylation

2.94139265

Protein homooligomerization

2.928929122

Cellular amino acid metabolic process

2.840660025

Positive regulation of I-kappaB kinase/NF-kappaB cascade

2.757555609

Cell adhesion

2.737533753

Fatty acid biosynthetic process

2.728528708

Interspecies interaction between organisms

2.696985024

Osteoblast differentiation

2.69309327

Transmembrane receptor protein tyrosine kinase signaling pathway

2.546626794

Signal transduction

2.529953417

Activation of MAPK activity

2.449230494

Innate immune response

2.367216687

Skeletal system development

2.319554606

Response to oxidative stress

2.273773923

Response to hypoxia

2.15335599

Cell proliferation

2.122933884

Cell death

2.057224026

Multicellular organismal development

1.901434245

Negative regulation of cell proliferation

1.840545992

Lipid metabolic process

1.78765674

Positive regulation of transcription from RNA polymerase II promoter

0.643002114

Transmembrane transport

0.599113562

Small GTPase-mediated signal transduction

0.433824648

Regulation of transcription, DNA-dependent

0.407975625

Intracellular protein transport

0.399553337

Axon guidance

0.360014205

Translation

0.261432403

DNA repair

0.23247554

Antigen processing and presentation of peptide antigen via MHC class I

0.174552342

Positive regulation of transcription, DNA-dependent

0.17004361

Protein folding

0.164970709

Protein ubiquitination

0.154291802

mRNA processing

0.152926388

Xenobiotic metabolic process

0.12042287

Synaptic transmission

0.116172651

Negative regulation of transcription, DNA-dependent

0.112945633

Mitotic cell cycle

0.104100493

Fibroblast growth factor receptor signaling pathway

0.101950925

Transcription, DNA-dependent

0.016632033

Transcription, DNA-dependent

$-0.039880623$

Translation

$-0.062686789$

Blood coagulation

Intracellular protein transport

DNA repair

Regulation of small GTPase-mediated signal transduction

Viral reproduction

$-0.162175997$

Innate immune response

$-0.227046396$

Mitotic cell cycle 
Table IV. Continued.

GO name

Positive regulation of transcription, DNA-dependent

Cytokine-mediated signaling pathway

Negative regulation of transcription, DNA-dependent

Immune response

Positive regulation of transcription from RNA polymerase II promoter

Negative regulation of transcription from RNA polymerase II promoter

Small GTPase-mediated signal transduction

Protein transport

Proteolysis

Regulation of transcription, DNA-dependent

Transport

Signal transduction

Positive regulation of cell proliferation

Response to ethanol

Regulation of cell shape

Cell differentiation

Kidney development

Cell-cell signaling

Homophilic cell adhesion

Muscle organ development

Neuron differentiation

Chromatin modification

Lipid catabolic process

Regulation of cell growth

Sodium ion transport

Calcium ion transport

Inner ear morphogenesis

Fatty acid metabolic process

Response to stimulus

Palate development

Neuron projection morphogenesis

Potassium ion transport

Transmembrane receptor protein tyrosine kinase signaling pathway

Cellular response to insulin stimulus

Memory

Response to hormone stimulus

Nervous system development

Cell adhesion

Embryonic digit morphogenesis

Muscle contraction

Positive regulation of glucose import

Learning or memory

Synapse assembly

Odontogenesis

Multicellular organismal development

Positive regulation of canonical Wnt receptor signaling pathway

Behavior

Regulation of heart contraction

Response to morphine
Enrichment score

$-0.254833747$

$-0.264766564$

$-0.270823316$

$-0.355455602$

$-0.385450859$

$-0.389854531$

$-0.404535246$

$-0.408638731$

$-0.541854957$

$-0.628876401$

$-1.651693671$

$-1.661658778$

$-1.826982685$

$-2.273925035$

$-2.419618529$

$-2.426430518$

$-2.458065857$

$-2.530440751$

$-2.617008461$

$-2.736337463$

$-2.825179589$

$-2.900517711$

$-2.95971195$

$-2.986376022$

$-2.99537113$

$-3.107697548$

$-3.139088432$

$-3.1873821$

$-3.288568834$

$-3.333928404$

$-3.341610266$

$-3.452997275$

$-3.489344615$

$-3.489344615$

$-3.511522653$

$-3.511522653$

$-3.540414928$

$-3.575097603$

$-3.710683639$

$-3.732970027$

$-3.9462826$

$-4.062349736$

$-4.14359673$

$-4.14359673$

$-4.157006428$

$-4.213827183$

$-4.2498428$

$-4.361680769$

$-4.361680769$ 
Table IV. Continued.

GO name

Neurogenesis

Negative regulation of insulin secretion

Negative regulation of epithelial cell proliferation

Branching morphogenesis of a tube

Embryonic skeletal system development

Positive regulation of mesenchymal cell proliferation

Tissue regeneration

Negative regulation of Wnt receptor signaling pathway

Central nervous system development

Neurotransmitter transport

Retinal ganglion cell axon guidance

Positive regulation of blood pressure

Calcium-dependent cell-cell adhesion

Activation of phospholipase $\mathrm{C}$ activity by $\mathrm{G}$-protein coupled receptor protein signaling

Pathway coupled to IP3 second messenger

Middle ear morphogenesis

Eye development

Positive regulation of epithelial cell proliferation

Positive regulation of cell differentiation

Mammary gland development

Regulation of smooth muscle contraction

Positive regulation of tyrosine phosphorylation of Stat5 protein

Hemopoietic stem cell proliferation

Neural tube development

Calcium ion transport into cytosol

Mesonephros development

Peptide cross-linking via chondroitin 4-sulfate glycosaminoglycan

Prostate gland growth

Ion transport

Regulation of synaptic transmission

Positive regulation of insulin-like growth factor receptor signaling pathway

Positive regulation of cyclin-dependent protein kinase activity

Vagina development

Cardiac muscle tissue development

Transmembrane receptor protein tyrosine phosphatase signaling pathway

Choline metabolic process

Negative regulation of epinephrine secretion

Protein insertion into membrane

Type II pneumocyte differentiation

Activation of protein kinase B activity

Metabolic process

Regulation of respiratory gaseous exchange by neurological system process

Creatine metabolic process

Retinal metabolic process

Peptide biosynthetic process

Growth hormone receptor signaling pathway

Hormone-mediated signaling pathway

Rhythmic process

Cardiac left ventricle morphogenesis
Enrichment score

$-4.479564033$

$-4.603996367$

$-4.73553912$

$-4.73553912$

$-4.93285325$

$-4.972316076$

$-5.022541491$

$-5.179495913$

$-5.217862549$

$-5.404691387$

$-5.404691387$

$-5.404691387$

$-5.452100961$

$-5.599455041$

$-5.715305835$

$-6.542521153$

$-6.605733918$

$-6.683220533$

$-6.90599455$

$-6.90599455$

$-6.90599455$

$-6.90599455$

$-7.206255183$

$-7.312229524$

$-7.769243869$

$-7.769243869$

$-7.769243869$

$-8.119209809$

$-8.28719346$

$-8.28719346$

$-8.28719346$

$-8.28719346$

$-8.879135851$

$-9.207992734$

$-9.207992734$

$-9.207992734$

$-9.207992734$

$-9.207992734$

$-9.562146301$

$-9.749639365$

$-10.35899183$

$-10.35899183$

$-10.35899183$

$-10.35899183$

$-10.35899183$

$-11.30071836$

$-11.50999092$

$-11.8388478$ 
Table IV. Continued.

GO name

Positive regulation of cyclin-dependent protein kinase activity involved in G1/S

Positive regulation of lymphocyte proliferation

Ovulation cycle

Negative regulation of norepinephrine secretion

Taurine metabolic process

Negative regulation of actin filament polymerization

Positive regulation of potassium ion transport

Urinary bladder development

Morphogenesis of an epithelial fold

Ciliary neurotrophic factor-mediated signaling pathway

Aromatic compound catabolic process

Negative regulation of phagocytosis

Tertiary branching involved in mammary gland duct morphogenesis

Cellular response to heparin

Regulation of vasodilation

Nucleoside triphosphate catabolic process

Saliva secretion

Female genitalia morphogenesis

Smooth muscle contraction involved in micturition

Regulation of prostatic bud formation

Pericardium morphogenesis

Lateral sprouting involved in mammary gland duct morphogenesis

Regulation of protein metabolic process

Negative regulation of the force of heart contraction involved in baroreceptor response to

Increased systemic arterial blood pressure

Renin secretion into blood stream

Regulation of thyroid hormone mediated signaling pathway

Negative regulation of leukocyte chemotaxis

Pyruvate transport

Nucleoside diphosphate catabolic process

Glycolate metabolic process

Negative regulation of lamellipodium assembly

Muscle hypertrophy

Myotube cell development

Mevalonate transport

Male somatic sex determination

Spinal cord patterning

Orbitofrontal cortex development

Cell-cell adhesion involved in neuronal-glial interactions involved in cerebral cortex radial

glia guided migration

Corticospinal neuron axon guidance through spinal cord

Neural plate mediolateral regionalization

Cellular potassium ion homeostasis

Regulation of mismatch repair

Positive regulation of phospholipase A2 activity

Retinol transport

Response to luteinizing hormone stimulus

Positive regulation of locomotion

Sequestering of neurotransmitter
Enrichment score

$-11.8388478$

$-11.8388478$

$-13.8119891$

$-13.8119891$

$-13.8119891$

$-13.8119891$

$-13.8119891$

$-13.8119891$

$-13.8119891$

$-13.8119891$

$-16.57438692$

$-16.57438692$

$-16.57438692$

$-16.57438692$

$-17.7582717$

$-20.71798365$

$-20.71798365$

$-20.71798365$

$-20.71798365$

$-20.71798365$

$-27.6239782$

$-27.6239782$

$-41.4359673$

$-41.4359673$

$-41.4359673$

$-41.4359673$

$-41.4359673$

$-41.4359673$

$-41.4359673$

$-41.4359673$

$-41.4359673$

$-41.4359673$

$-41.4359673$

$-41.4359673$

$-41.4359673$

$-41.4359673$

$-41.4359673$

$-41.4359673$

$-41.4359673$

$-41.4359673$

$-41.4359673$

$-41.4359673$

$-41.4359673$

$-41.4359673$

$-41.4359673$

$-41.4359673$

$-41.4359673$ 
Table IV. Continued.

GO name

Enrichment score

Carnitine catabolic process

$-41.4359673$

Homocysteine catabolic process

$-41.4359673$

Regulation of adenylate cyclase activity

$-41.4359673$

Phosphatidic acid metabolic process

$-41.4359673$

Regulation of saliva secretion

$-41.4359673$

Paraxial mesoderm structural organization

$-41.4359673$

Intermediate mesoderm development

$-41.4359673$

Urothelial cell proliferation

$-41.4359673$

Induction of negative chemotaxis

$-41.4359673$

Regulation of lipid catabolic process

$-41.4359673$

Negative regulation of small GTPase-mediated signal transduction

$-41.4359673$

Micturition

$-41.4359673$

Activation of prostate induction by androgen receptor signaling pathway

$-41.4359673$

Neural plate pattern specification

$-41.4359673$

Dermatome development

$-41.4359673$

Negative regulation of activation-induced cell death of T cells

$-41.4359673$

Cellular response to chemical stimulus

$-41.4359673$

Negative regulation of smooth muscle cell chemotaxis

$-41.4359673$

Negative regulation of mononuclear cell migration

$-41.4359673$

Pattern specification involved in metanephros development

$-41.4359673$

Negative regulation of neutrophil chemotaxis

$-41.4359673$

Metanephric cap mesenchymal cell proliferation involved in metanephros development

$-41.4359673$

Positive regulation of non-canonical Wnt receptor signaling pathway

$-41.4359673$

Positive regulation of Wnt receptor signaling pathway involved in dorsal/ventral axis specification

$-41.4359673$

indegree of the gene and the number of target genes of a gene is its outdegree. The character of genes is described by betweenness centrality measures reflecting the importance of a node in a graph relative to other nodes. For a graph $\mathrm{G}:(\mathrm{V}, \mathrm{E})$ with $\mathrm{n}$ vertices, the relative betweenness centrality $C_{B}^{\prime}(v)$ is defined by:

$$
C_{B}^{\prime}(V)=\frac{2}{n^{2}-3 n+2} \sum_{\substack{s \sim V \sim t \in V \\ s \neq t}} \frac{\sigma_{s t}(v)}{\sigma_{s t}}
$$

where $\sigma_{s t}$ is the number of shortest paths from s to t, and $\sigma_{s t}(v)$ is the number of shortest paths from $s$ to that pass through a vertex v (24-28).

Data analysis. Numerical data are presented as the means \pm standard deviation (SD). Differences between means were analyzed using the Student's t-test. All statistical analyses were performed using SPSS 13.0 software (SPSS, Inc., Chicago, IL, USA).

\section{Results}

Clinical characteristics of the two sample groups. The characteristics of the 5 consecutive patients with CTEPH (3 male, 2 female) enrolled in the study are presented in Table I. In addition, tissue from healthy volunteers was obtained from donors of lung transplants and matched to the patients with CTEPH. All patients with CTEPH did not have lung cancer and underwent anti-vitamin $\mathrm{K}$ treatment using warfarin. The median D-dimer level of the patients with CTEPH was $0.499 \mu \mathrm{g} / \mathrm{ml}$ (range, $0-1.32 \mu \mathrm{g} / \mathrm{ml}$ ).

CTEPH-related differential gene expression profiles. Genomewide transcriptional profiling of tumors has demonstrated that extensive gene expression occurs after the formation of CTEPH. To investigate the possible changes in gene expression, microarray analysis was used to analyze the gene expression profiles in the patients with CTEPH and normal tissue groups and 1,614 genes with statistically significant changes in expression were identified. Of these, 880 genes were upregulated in the CTEPH samples and 734 were downregulated. Ten genes that were the most significantly upregulated or downregulated according to their P-values are listed (Tables II and III). Hierarchical clustering revealed systematic variations in the expression of genes between the two groups (Fig. 1). The results demonstrated that these differential probes could clearly separate the two groups from the whole samples.

GO analysis of differentially expressed genes in CTEPH and GO map. Significant progress in data mining has provided a wide range of bioinformatics analysis options. For example, 


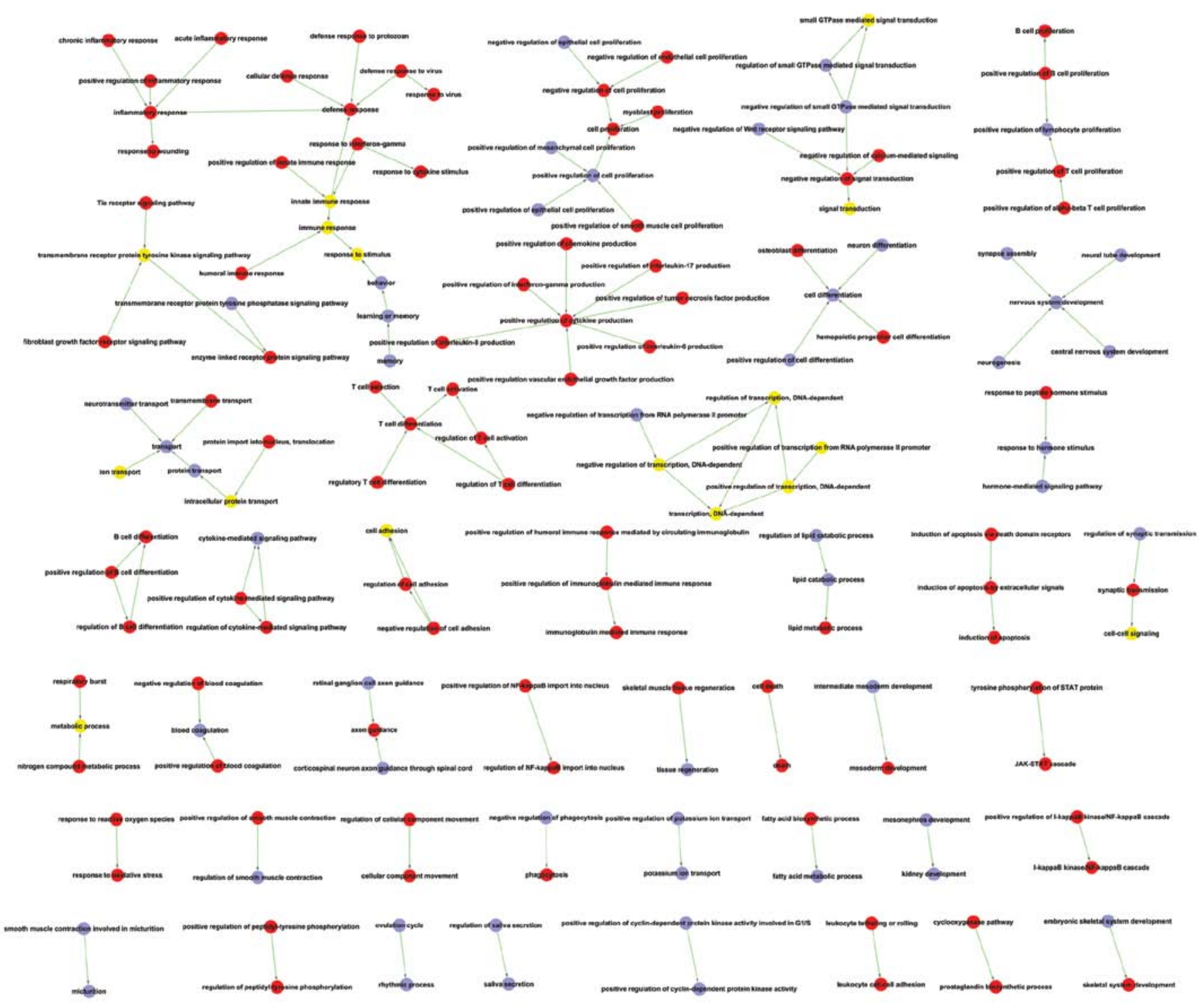

Figure 2. GO map of significant differentially expressed genes: red circles represent the GO categories of upregulated genes, lavender circles represent the GO categories of downregulated genes and yellow circles represent the GO categories associated with both upregulated and downregulated genes.

GO, which has been proven to be extremely useful for the mining of functional and biological significance from very large datasets $(17,18)$, can produce a controlled vocabulary used for dynamic maintenance and interoperability between genome databases. GO analysis of the differentially expressed genes in the two groups was performed. A total of $235 \mathrm{GO}$ items associated with upregulated genes and $177 \mathrm{GO}$ items associated with downregulated genes in the two groups were obtained (Table IV). For the GO items listed in the table, a GO map was constructed to further define the results of GO analysis (Fig. 2). In the GO map, items regarding defense response were the most common between the two groups, suggesting that the formation of thrombi was mainly caused by tissue response to various stimuli, such as inflammation and immune response. Furthermore, items regarding cell proliferation, signal transduction and cytokine production were also very common (high enrichment score). All these items indicated that apart from the traditional knowledge of the role of thrombosis in the development of CTEPH, other mechanisms, such as signaling pathway and cytokines may also play an important role in its pathogenesis.
Pathway analysis of differentially expressed genes in CTEPH and Path-Net. To determine the involvment of signal transduction pathways in CTEPH, related pathways were analyzed according to the functions and interactions of the differentially expressed genes. By using pathway analysis with the threshold of significance defined on the basis of $\mathrm{P}<0.05$, a great number of significant pathways was found (Tables V and VI). The high enriched pathways targeted by overexpressed genes were involved in cytokine-cytokine receptor interaction, leishmaniasis and cell adhesion molecules (CAMs). By contrast, significant pathways corresponding to underexpressed genes appeared to be responsible for focal adhesion, neuroactive ligand-receptor interaction and arrhythmogenic right ventricular cardiomyopathy (ARVC). However, for the pathways listed which seemed to not be relevant to CTEPH, Path-Net was used to analyze the different pathways to identify the most important ones (Fig. 3). In Path-Net, the MAPK signaling pathway and apoptosis had the largest enrichment degree, which suggests that they are not the most significant variation pathways but participate in pathway regulation. Identifying these pathways 
Table V. Upregulated significant pathways.

Pathway name
Cytokine-cytokine receptor interaction
Leishmaniasis
Cell adhesion molecules (CAMs)
Chagas disease
T cell receptor signaling pathway
Hematopoietic cell lineage
Natural killer cell mediated cytotoxicity
Chemokine signaling pathway
Primary immunodeficiency
Phagosome
Antigen processing and presentation
Intestinal immune network for IgA production
Malaria
Toll-like receptor signaling pathway
Allograft rejection
Graft-versus-host disease
B cell receptor signaling pathway
Type I diabetes mellitus
Viral myocarditis
NOD-like receptor signaling pathway

Asthma

Jak-STAT signaling pathway

Leukocyte transendothelial migration

Amoebiasis

Systemic lupus erythematosus

Autoimmune thyroid disease

Fc gamma R-mediated phagocytosis

Fc epsilon RI signaling pathway

Complement and coagulation cascades

Apoptosis

Lysosome

Pathways in cancer

Regulation of actin cytoskeleton

p53 signaling pathway

Cytosolic DNA-sensing pathway

Neuroactive ligand-receptor interaction

Calcium signaling pathway

Epithelial cell signaling in

Helicobacter pylori infection

MAPK signaling pathway

RIG-I-like receptor signaling pathway

Neurotrophin signaling pathway

Pantothenate and CoA biosynthesis

Acute myeloid leukemia

Arachidonic acid metabolism

Focal adhesion

TGF-beta signaling pathway

Prion diseases
Table V. Continued.

\begin{tabular}{lc}
\hline Pathway name & -LgP \\
\hline Olfactory transduction & 2.139616901 \\
mTOR signaling pathway & 2.121221511 \\
Amyotrophic lateral sclerosis (ALS) & 2.079595295 \\
Endocytosis & 1.906955325 \\
VEGF signaling pathway & 1.890777366 \\
Aldosterone-regulated sodium reabsorption & 1.851879925 \\
Shigellosis & 1.780192486 \\
Glycosaminoglycan biosynthesis - keratan & 1.771193081 \\
sulfate & \\
Small cell lung cancer & 1.633206157 \\
Other glycan degradation & 1.615330588 \\
Salivary secretion & 1.530885213 \\
Renal cell carcinoma & 1.501166586 \\
Pancreatic cancer & 1.501166586 \\
Melanoma & 1.473244623 \\
Ether lipid metabolism & 1.40495844 \\
\hline
\end{tabular}

-LgP, negative logarithm of the P-value.

10.72782064

10.43654793

9.858981253

8.781008205

8.780882537

8.69910665

8.385599375

8.176130358

8.170383587

7.492623136

6.80371883

6.801648207

5.705278343

5.334893435

4.192720575

4.003028031

3.535108478

3.092429362

3.078524076

2.822547274

2.818702804

2.752907643

2.693488553

2.625676671

2.610488424

2.603797719

2.514704889

2.36365754

2.223171679

2.198269973 may help us regulate the related pathways and control the development of CTEPH.

Signal transduction networks in CTEPH. According to the literature and experimental records in the databases, $440(276+164)$ genes appearing in previous $113(62+51)$ pathways were collected and a diagram of the gene interaction network was drawn up based on these genes (Fig. 4). The total number of genes in the network was 232, and the particular associations between them are listed in Table VII. In the network, cycle nodes represent genes, and the edges between two nodes represent the interactions between genes, which were quantified by betweenness centrality. Betweenness centrality within the network which contains both the direct regulation by degree and the signal transmitting between the genes represents the size of the cycle node. The higher the betweenness centrality, the more common the gene within the network. The clustering coefficient can be used to estimate the complexity of interactions among genes that neighbor the core gene with the exception of core gene participation. The lower the clustering coefficient, the more independent of the core gene is the interaction among genes in the neighborhood of the core gene. Janus kinase 3 (JAK3), guanine nucleotide binding protein (G protein), alpha $15(\mathrm{Gq}$ class) (GNA15), mitogen-activated protein kinase 13 (MAPK13), arrestin, beta 2 (ARRB2) and coagulation factor II (thrombin) receptor (F2R) were the five main central genes identified by betweenness centrality.

\section{Discussion}

Several clinical and therapeutic factors have been reported as significant to the occurrence of CTEPH. The pathophysiology of CTEPH remains incompletely understood. In most cases 
Table VI. Pathways associated with significantly downregulated genes.

\begin{tabular}{|c|c|}
\hline Pathway name & $-\mathrm{LgP}$ \\
\hline Focal adhesion & 8.1140073 \\
\hline Neuroactive ligand-receptor interaction & 5.712988 \\
\hline $\begin{array}{l}\text { Arrhythmogenic right ventricular } \\
\text { cardiomyopathy (ARVC) }\end{array}$ & 5.5013372 \\
\hline Calcium signaling pathway & 5.445408 \\
\hline Wnt signaling pathway & 5.1186354 \\
\hline Vascular smooth muscle contraction & 5.0207839 \\
\hline Long-term depression & 4.8678343 \\
\hline Aldosterone-regulated sodium reabsorption & 3.9213362 \\
\hline Axon guidance & 3.8465848 \\
\hline Dilated cardiomyopathy & 3.8147938 \\
\hline Hypertrophic cardiomyopathy (HCM) & 3.4512102 \\
\hline ErbB signaling pathway & 3.2950005 \\
\hline Salivary secretion & 3.2203532 \\
\hline Adherens junction & 3.1261703 \\
\hline Pathways in cancer & 3.0889176 \\
\hline Pancreatic secretion & 2.8145968 \\
\hline Glycine, serine and threonine metabolism & 2.7224771 \\
\hline Glioma & 2.7174562 \\
\hline ECM-receptor interaction & 2.6818514 \\
\hline Progesterone-mediated oocyte maturation & 2.6485594 \\
\hline Glycerolipid metabolism & 2.6032586 \\
\hline Long-term potentiation & 2.5263793 \\
\hline Regulation of actin cytoskeleton & 2.3885129 \\
\hline Tyrosine metabolism & 2.3264949 \\
\hline Phosphatidylinositol signaling system & 2.2235491 \\
\hline GnRH signaling pathway & 2.204073 \\
\hline Melanogenesis & 2.204073 \\
\hline Nicotinate and nicotinamide metabolism & 2.1809844 \\
\hline $\mathrm{ABC}$ transporters & 2.093767 \\
\hline Olfactory transduction & 2.080365 \\
\hline Histidine metabolism & 2.0047222 \\
\hline Cell adhesion molecules (CAMs) & 1.9933196 \\
\hline Oocyte meiosis & 1.9319734 \\
\hline MAPK signaling pathway & 1.9265796 \\
\hline Gap junction & 1.9104997 \\
\hline Insulin signaling pathway & 1.8902518 \\
\hline PPAR signaling pathway & 1.8327772 \\
\hline Melanoma & 1.8327772 \\
\hline Fc gamma R-mediated phagocytosis & 1.7609805 \\
\hline Phenylalanine metabolism & 1.7586389 \\
\hline Gastric acid secretion & 1.7471867 \\
\hline Arginine and proline metabolism & 1.6184534 \\
\hline Inositol phosphate metabolism & 1.5877798 \\
\hline Circadian rhythm - mammal & 1.5137608 \\
\hline Tryptophan metabolism & 1.5097806 \\
\hline Amoebiasis & 1.4980899 \\
\hline Chemokine signaling pathway & 1.4705506 \\
\hline
\end{tabular}

Table VI. Continued.

\begin{tabular}{lc}
\hline Pathway name & -LgP \\
\hline Purine metabolism & 1.4329084 \\
Prostate cancer & 1.3808613 \\
Fatty acid metabolism & 1.3705322 \\
Valine, leucine and isoleucine degradation & 1.3705322 \\
\hline -LgP, negative logarithm of the P-value. & \\
\hline
\end{tabular}

it is associated with a history of acute venous thromboembolism (29); however, in a small percentage of patients, thrombi do not resolve after an acute event and the reasons for this are unclear. The current knowledge is based on a triad of enhanced thrombosis (7,30), disturbed thrombolysis (31-33) and inflammation (34). A number of novel prognostic factors, such as cytological features, standard karyotyping, fluorescence in situ hybridization, centromeric probes, single nucleotide polymorphism and gene expression profiling have been investigated. Using the advanced and inexpensive technique of microarray, new genes which may affect the development of CTEPH can be identified.

In this study, to investigate variations in gene expression profiles and signaling pathways in CTEPH, 10 samples were divided into a normal (control) and CTEPH group to identify CTEPH-related differentially expressed genes. The expression of the upregulated genes was higher in the CTEPH group compared with the control group. Gene chips have become a useful tool for studying the development and progression of tumors owing to the high-throughout, but it remains difficult to predict patients with CTEPH, mainly due to the high number of variations in CTEPH and the great challenge in interpreting numerous complex data produced by the microarray (35) and determining the main responsible genes. The present study made use of bioinformatics the method to analyze functions and pathways of the differentially expressed genes, and further clarified their biological significance, and defined the key genes that affect the development of CTEPH.

More than 1,600 genes were differentially upregulated or downregulated in CTEPH in this study. The first upregulated differentially expressed gene in CTEPH, oxidized low density lipoprotein (lectin-like) receptor 1 (OLR1), has been studied in several cardiovascular diseases, such as atherosclerosis for its polymorphisms (36), and recently Wynants et al found that it is highly expressed CTEPH (5). The second most significantly upregulated gene, intereukin (IL)8, has been found to be associated with hemodynamic instability following PEA in patients with CTEPH (37). The role of the third most upregulated gene, secreted phosphoprotein 1 (SPP1), which encodes osteopontin, in CTEPH is poorly understood. Most of the genes that were strongly downregulated showed close associations with tumors, chemokines and lipids, including the gene for CXCL14, which is a type of chemokine ligand involved in the regulation of tumors $(38,39)$. Heparanase 2 (HPSE2) encodes a specific enzyme and is associated with urofacial syndrome (40). None of these genes were found to be associated with CTEPH. As the sample number we used in this study was limited, we tried to investigate the microarray results using another method. 


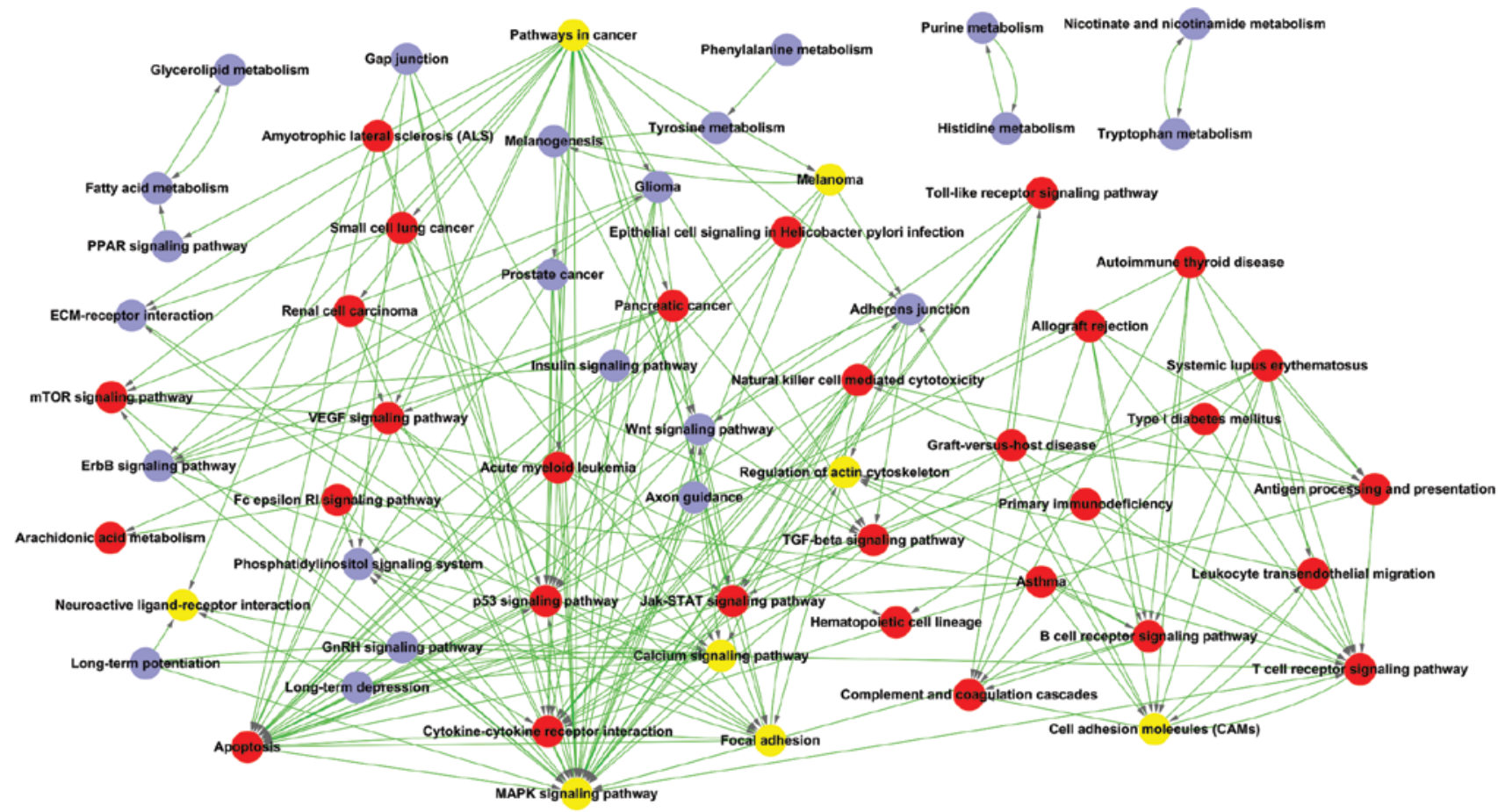

Figure 3. Path-Net network of significantly differentially expressed genes: red circles represent the pathways associated with upregulated genes, lavender circles represent the pathways associated with downregulated genes and yellow circles represent the pathways associated with both up- and downregulated genes.

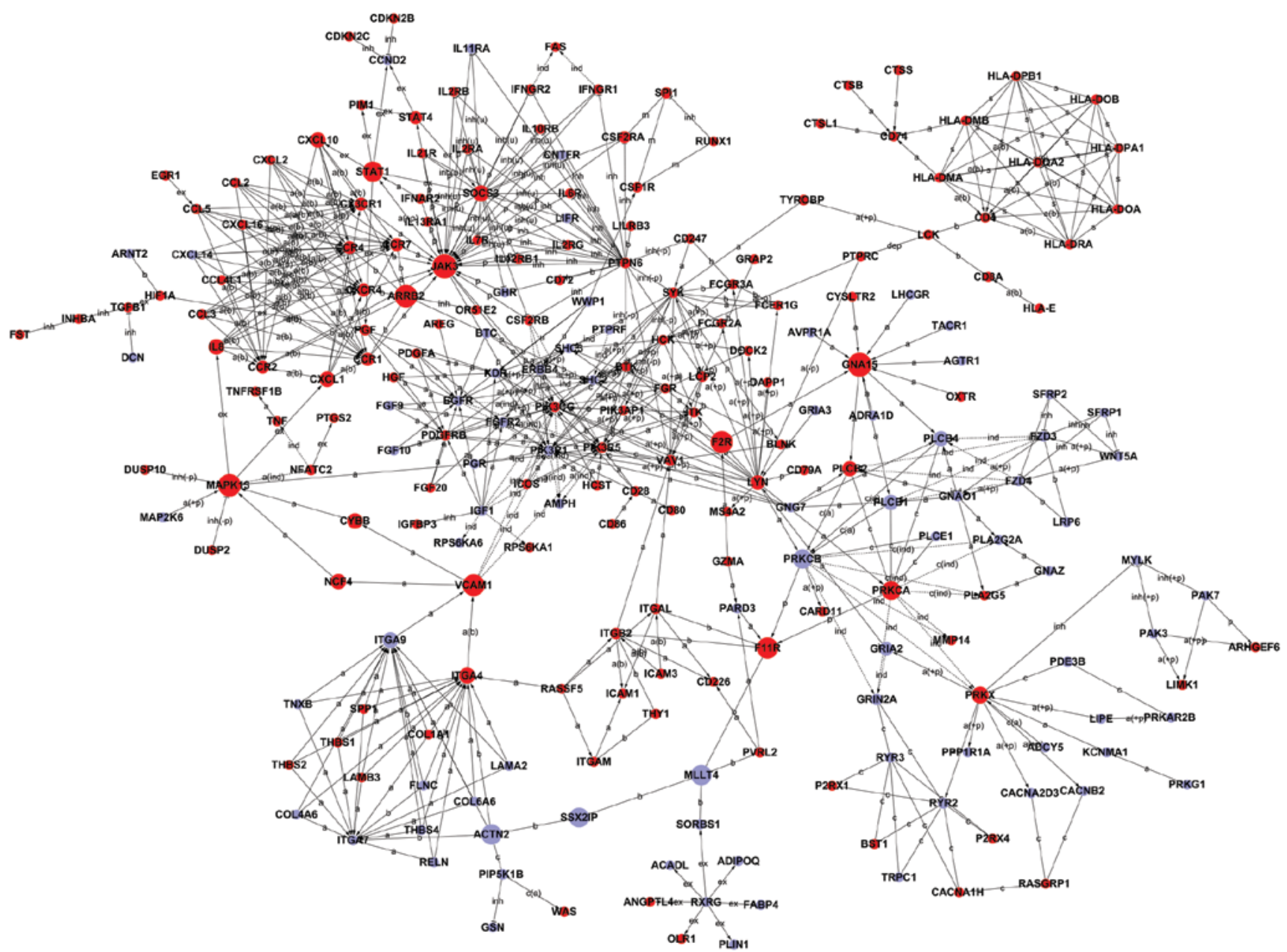

Figure 4. Signal transduction networks of CTEPH-related genes. Circles represent genes, red circles represent upregulated genes, and blue circles represent downregulated genes. Arrows represent the activation of (a); straight line represents combinations; dotted line represents indirect effects; a, represents activation; ex, represents gene expression; b, represents binding; c, represents compound; ind, represents indirect effects; inh, represents inhibition; $\mathrm{u}$, represents ubiquination, $\mathrm{s}$, represents state change; detailed annotation listed in Table VII. 
Table VII. Characteristics of genes.

\begin{tabular}{|c|c|c|c|c|c|c|}
\hline $\begin{array}{l}\text { Gene } \\
\text { symbol }\end{array}$ & Description & $\begin{array}{l}\text { Betweenness } \\
\text { centrality }\end{array}$ & Degree & Indegree & Outdegree & Style \\
\hline JAK3 & Janus kinase 3 & 0.038452356 & 31 & 26 & 5 & Up \\
\hline GNA15 & $\begin{array}{l}\text { Guanine nucleotide binding protein } \\
\text { (G protein), alpha } 15 \text { (Gq class) }\end{array}$ & 0.037599143 & 11 & 8 & 3 & Up \\
\hline MAPK13 & Mitogen-activated protein kinase 13 & 0.033950795 & 9 & 6 & 3 & Up \\
\hline ARRB2 & Arrestin, beta 2 & 0.033861892 & 8 & 7 & 8 & Up \\
\hline $\mathrm{F} 2 \mathrm{R}$ & Coagulation factor II (thrombin) receptor & 0.032585932 & 3 & 2 & 2 & Up \\
\hline VCAM1 & Vascular cell adhesion molecule 1 & 0.031990127 & 7 & 2 & 5 & Up \\
\hline F11R & F11 receptor & 0.03029902 & 6 & 6 & 3 & Up \\
\hline MLLT4 & $\begin{array}{l}\text { Myeloid/lymphoid or mixed-lineage leukemia } \\
\text { (trithorax homolog, Drosophila); translocated to, } 4\end{array}$ & 0.028330801 & 4 & 4 & 4 & Down \\
\hline STAT1 & Signal transducer and activator of transcription $1,91 \mathrm{kDa}$ & 0.027727017 & 7 & 2 & 5 & Up \\
\hline ACTN2 & Actinin, alpha 2 & 0.027721674 & 5 & 5 & 5 & Down \\
\hline SSX2IP & Synovial sarcoma, $\mathrm{X}$ breakpoint 2 interacting protein & 0.026250152 & 2 & 2 & 2 & Down \\
\hline PRKCB & Protein kinase $\mathrm{C}$, beta & 0.02479466 & 12 & 5 & 8 & Down \\
\hline PRKCA & Protein kinase $\mathrm{C}$, alpha & 0.024281711 & 11 & 5 & 10 & Up \\
\hline PRKX & Protein kinase, $\mathrm{X}$-linked & 0.018822441 & 12 & 4 & 9 & Up \\
\hline ITGA4 & $\begin{array}{l}\text { Integrin, alpha } 4 \text { (antigen CD49D, alpha } 4 \text { subunit } \\
\text { of VLA-4 receptor) }\end{array}$ & 0.016703185 & 15 & 14 & 3 & Up \\
\hline SOCS3 & Suppressor of cytokine signaling 3 & 0.01636563 & 21 & 2 & 19 & Up \\
\hline ITGA9 & Integrin, alpha 9 & 0.016034992 & 14 & 13 & 3 & Down \\
\hline CXCL1 & $\begin{array}{l}\text { Chemokine (C-X-C motif) ligand } 1 \\
\text { (melanoma growth stimulating activity, alpha) }\end{array}$ & 0.015128782 & 7 & 1 & 6 & Up \\
\hline IL8 & Interleukin 8 & 0.015128782 & 7 & 1 & 6 & Up \\
\hline NCF4 & Neutrophil cytosolic factor $4,40 \mathrm{kDa}$ & 0.014984515 & 2 & 1 & 1 & Up \\
\hline CYBB & Cytochrome b-245, beta polypeptide & 0.014984515 & 2 & 1 & 1 & Up \\
\hline CXCL10 & Chemokine (C-X-C motif) ligand 10 & 0.014593392 & 7 & 1 & 6 & Up \\
\hline PLCB4 & Phospholipase $\mathrm{C}$, beta 4 & 0.01422471 & 7 & 6 & 2 & Down \\
\hline PLCB1 & Phospholipase C, beta 1 (phosphoinositide-specific) & 0.01422471 & 7 & 6 & 2 & Down \\
\hline PLCB2 & Phospholipase C, beta 2 & 0.01422471 & 7 & 6 & 2 & Up \\
\hline LYN & v-yes-1 Yamaguchi sarcoma viral related oncogene homolog & 0.011954016 & 20 & 3 & 17 & Up \\
\hline GRIA2 & Glutamate receptor, ionotropic, AMPA 2 & 0.010419088 & 3 & 1 & 2 & Down \\
\hline STAT4 & Signal transducer and activator of transcription 4 & 0.008717991 & 4 & 1 & 3 & Up \\
\hline CCR7 & Chemokine (C-C motif) receptor 7 & 0.008388993 & 12 & 11 & 2 & Up \\
\hline CCR4 & Chemokine (C-C motif) receptor 4 & 0.008388993 & 12 & 11 & 2 & Up \\
\hline CCR2 & Chemokine (C-C motif) receptor 2 & 0.008388993 & 12 & 11 & 2 & Up \\
\hline CX3CR1 & Chemokine (C-X3-C motif) receptor 1 & 0.008388993 & 12 & 11 & 2 & Up \\
\hline CCR1 & Chemokine (C-C motif) receptor 1 & 0.008388993 & 12 & 11 & 2 & Up \\
\hline CXCR4 & Chemokine (C-X-C motif) receptor 4 & 0.008388993 & 12 & 11 & 2 & Up \\
\hline CSF2RA & $\begin{array}{l}\text { Colony stimulating factor } 2 \text { receptor, alpha, } \\
\text { low-affinity (granulocyte-macrophage) }\end{array}$ & 0.005161547 & 4 & 3 & 2 & Up \\
\hline ITGB2 & $\begin{array}{l}\text { Integrin, beta } 2 \text { (complement component } 3 \\
\text { receptor } 3 \text { and } 4 \text { subunit) }\end{array}$ & 0.004818256 & 7 & 4 & 5 & Up \\
\hline SPI1 & $\begin{array}{l}\text { Spleen focus forming virus (SFFV) proviral } \\
\text { integration oncogene spi } 1\end{array}$ & 0.003699643 & 3 & 3 & 2 & Up \\
\hline PGF & Placental growth factor & 0.003543193 & 5 & 2 & 3 & Up \\
\hline GRIN2A & Glutamate receptor, ionotropic, N-methyl D-aspartate $2 \mathrm{~A}$ & 0.003531713 & 5 & 5 & 2 & Down \\
\hline VAV1 & Vav 1 guanine nucleotide exchange factor & 0.002788411 & 11 & 11 & 5 & Up \\
\hline RYR2 & Ryanodine receptor 2 (cardiac) & 0.002768397 & 7 & 7 & 6 & Down \\
\hline
\end{tabular}


Table VII. Continued.

\begin{tabular}{|c|c|c|c|c|c|c|}
\hline $\begin{array}{l}\text { Gene } \\
\text { symbol }\end{array}$ & Description & $\begin{array}{l}\text { Betweenness } \\
\text { centrality }\end{array}$ & Degree & Indegree & Outdegree & Style \\
\hline NFATC2 & $\begin{array}{l}\text { Nuclear factor of activated T-cells, cytoplasmic, } \\
\text { calcineurin-dependent } 2\end{array}$ & 0.002250563 & 3 & 1 & 2 & Up \\
\hline SYK & Spleen tyrosine kinase & 0.002031231 & 17 & 8 & 12 & Up \\
\hline PIK3CG & Phosphoinositide-3-kinase, catalytic, gamma polypeptide & 0.001985436 & 23 & 21 & 5 & Up \\
\hline PIK3R5 & Phosphoinositide-3-kinase, regulatory subunit 5 & 0.001985436 & 23 & 21 & 5 & Up \\
\hline PIK3R1 & Phosphoinositide-3-kinase, regulatory subunit 1 (alpha) & 0.001985436 & 23 & 21 & 5 & Down \\
\hline ITGAL & $\begin{array}{l}\text { Integrin, alpha L [antigen CD11A (p180), lymphocyte } \\
\text { function-associated antigen 1; alpha polypeptide] }\end{array}$ & 0.001811094 & 6 & 3 & 4 & Up \\
\hline FZD3 & Frizzled homolog 3 (Drosophila) & 0.001625406 & 8 & 4 & 5 & Down \\
\hline FZD4 & Frizzled homolog 4 (Drosophila) & 0.001625406 & 8 & 4 & 5 & Down \\
\hline PTPN6 & Protein tyrosine phosphatase, non-receptor type 6 & 0.001615789 & 26 & 2 & 26 & Up \\
\hline PDE3B & Phosphodiesterase 3B, cGMP-inhibited & 0.001519611 & 2 & 2 & 2 & Down \\
\hline THY1 & Thy-1 cell surface antigen & 0.001513199 & 2 & 2 & 2 & Up \\
\hline PIP5K1B & Phosphatidylinositol-4-phosphate 5-kinase, type I, beta & 0.001487551 & 3 & 1 & 3 & Down \\
\hline LCK & Lymphocyte-specific protein tyrosine kinase & 0.001429845 & 4 & 3 & 3 & Up \\
\hline CSF1R & Colony stimulating factor 1 receptor & 0.001429845 & 3 & 3 & 2 & Up \\
\hline RYR3 & Ryanodine receptor 3 & 0.001408472 & 6 & 6 & 6 & Down \\
\hline TYROBP & TYRO protein tyrosine kinase binding protein & 0.001384962 & 2 & 1 & 1 & Up \\
\hline IFNAR2 & Interferon (alpha, beta and omega) receptor 2 & 0.001350765 & 4 & 2 & 2 & Up \\
\hline $\mathrm{LCP} 2$ & $\begin{array}{l}\text { Lymphocyte cytosolic protein } 2 \text { (SH2 domain containing } \\
\text { leukocyte protein of } 76 \mathrm{kDa})\end{array}$ & 0.001191975 & 6 & 5 & 4 & Up \\
\hline CD4 & CD4 molecule & 0.001077192 & 9 & 9 & 1 & Up \\
\hline PVRL2 & Poliovirus receptor-related 2 (herpesvirus entry mediator B) & 0.000865601 & 3 & 1 & 3 & Up \\
\hline FCGR3A & Fc fragment of IgG, low affinity IIIa, receptor (CD16a) & 0.00085349 & 5 & 5 & 3 & Up \\
\hline CCL5 & Chemokine (C-C motif) ligand 5 & 0.000801482 & 7 & 1 & 6 & Up \\
\hline SORBS1 & Sorbin and SH3 domain containing 1 & 0.000795071 & 2 & 2 & 1 & Down \\
\hline TNF & Tumor necrosis factor & 0.000756599 & 2 & 1 & 1 & Up \\
\hline EGFR & Epidermal growth factor receptor & 0.000745058 & 15 & 10 & 5 & Down \\
\hline ITK & IL2-inducible T-cell kinase & 0.00071535 & 8 & 7 & 2 & Up \\
\hline ITGA7 & Integrin, alpha 7 & 0.000649735 & 13 & 13 & 2 & Down \\
\hline PDGFRB & Platelet-derived growth factor receptor, beta polypeptide & 0.00059812 & 12 & 7 & 5 & Up \\
\hline KDR & $\begin{array}{l}\text { Kinase insert domain receptor (a type III receptor } \\
\text { tyrosine kinase) }\end{array}$ & 0.000530261 & 10 & 5 & 5 & Down \\
\hline BTK & Bruton agammaglobulinemia tyrosine kinase & 0.000391704 & 6 & 6 & 4 & Up \\
\hline CACNB2 & Calcium channel, voltage-dependent, beta 2 subunit & 0.000371888 & 2 & 2 & 1 & Down \\
\hline CACNA2D3 & Calcium channel, voltage-dependent, alpha $2 /$ delta subunit 3 & 0.000371888 & 2 & 2 & 1 & down \\
\hline IFNGR2 & Interferon gamma receptor 2 (interferon gamma transducer 1$)$ & 0.000368682 & 4 & 2 & 2 & Up \\
\hline IFNGR1 & Interferon gamma receptor 1 & 0.000368682 & 4 & 2 & 2 & Up \\
\hline FLNC & Filamin C, gamma & 0.00036227 & 3 & 3 & 3 & Down \\
\hline CACNA1H & $\begin{array}{l}\text { Calcium channel, voltage-dependent, } \mathrm{T} \text { type, } \\
\text { alpha } 1 \mathrm{H} \text { subunit }\end{array}$ & 0.000281511 & 3 & 3 & 3 & Up \\
\hline PARD3 & Par-3 partitioning defective 3 homolog (C. elegans) & 0.000278053 & 3 & 2 & 1 & Down \\
\hline RASGRP1 & $\begin{array}{l}\text { RAS guanyl releasing protein } 1 \text { (calcium and } \\
\text { DAG-regulated) }\end{array}$ & 0.000218003 & 3 & 3 & 3 & Up \\
\hline CD8A & CD8a molecule & 0.000134649 & 2 & 2 & 1 & Up \\
\hline IGF1 & Insulin-like growth factor 1 (somatomedin C) & 0.000121825 & 10 & 1 & 9 & Down \\
\hline HIF1A & $\begin{array}{l}\text { Hypoxia inducible factor } 1 \text {, alpha subunit (basic helix- } \\
\text { loop-helix transcription factor) }\end{array}$ & 0.000115413 & 3 & 1 & 3 & Up \\
\hline
\end{tabular}


Table VII. Continued.

\begin{tabular}{|c|c|c|c|c|c|c|}
\hline $\begin{array}{l}\text { Gene } \\
\text { symbol }\end{array}$ & Description & $\begin{array}{l}\text { Betweenness } \\
\text { centrality }\end{array}$ & Degree & Indegree & Outdegree & Style \\
\hline FGFR2 & Fibroblast growth factor receptor 2 & 0.000105796 & 9 & 6 & 3 & Down \\
\hline CSF2RB & $\begin{array}{l}\text { Colony stimulating factor } 2 \text { receptor, beta, low-affinity } \\
\text { (granulocyte-macrophage) }\end{array}$ & 0.000100025 & 6 & 2 & 4 & Up \\
\hline GNAO1 & $\begin{array}{l}\text { Guanine nucleotide binding protein ( } \mathrm{G} \text { protein), alpha } \\
\text { activating activity polypeptide } \mathrm{O}\end{array}$ & 7.69423E-05 & 7 & 2 & 5 & Down \\
\hline CD28 & CD28 molecule & 7.69423E-05 & 5 & 1 & 4 & Up \\
\hline ERBB4 & $\begin{array}{l}\text { v-erb - a erythroblastic leukemia viral oncogene } \\
\text { homolog } 4 \text { (avian) }\end{array}$ & $6.35843 \mathrm{E}-05$ & 7 & 2 & 5 & Down \\
\hline BLNK & B-cell linker & 5.79918E-05 & 3 & 3 & 2 & Up \\
\hline $\mathrm{HCK}$ & Hemopoietic cell kinase & $4.51375 \mathrm{E}-05$ & 10 & 1 & 9 & Up \\
\hline PLCE1 & Phospholipase C, epsilon 1 & 2.88534E-05 & 2 & 2 & 2 & Down \\
\hline HLA-DMB & Major histocompatibility complex, class II, DM beta & $1.92356 \mathrm{E}-05$ & 9 & 7 & 9 & Up \\
\hline HLA-DMA & Major histocompatibility complex, class II, DM alpha & $1.92356 \mathrm{E}-05$ & 9 & 7 & 9 & Up \\
\hline PIK3AP1 & Phosphoinositide-3-kinase adaptor protein 1 & $1.28237 \mathrm{E}-05$ & 4 & 4 & 3 & Up \\
\hline LRP6 & Low density lipoprotein receptor-related protein 6 & $1.28237 \mathrm{E}-05$ & 2 & 2 & 2 & Down \\
\hline CD247 & CD247 molecule & 9.61779E-06 & 3 & 2 & 2 & Up \\
\hline ITGAM & $\begin{array}{l}\text { Integrin, alpha } \mathrm{M} \text { (complement component } 3 \\
\text { receptor } 3 \text { subunit) }\end{array}$ & 8.54915E-06 & 3 & 2 & 2 & Up \\
\hline INHBA & Inhibin, beta $\mathrm{A}$ & $6.41186 \mathrm{E}-06$ & 2 & 1 & 1 & Up \\
\hline TRPC1 & $\begin{array}{l}\text { Transient receptor potential cation channel, subfamily } \mathrm{C} \text {, } \\
\text { member } 1\end{array}$ & $5.80121 \mathrm{E}-06$ & 2 & 2 & 2 & Down \\
\hline BST1 & Bone marrow stromal cell antigen 1 & $5.80121 \mathrm{E}-06$ & 2 & 2 & 2 & Up \\
\hline P2RX4 & Purinergic receptor $\mathrm{P} 2 \mathrm{X}$, ligand-gated ion channel, 4 & $5.80121 \mathrm{E}-06$ & 2 & 2 & 2 & Up \\
\hline P2RX1 & Purinergic receptor $\mathrm{P} 2 \mathrm{X}$, ligand-gated ion channel, 1 & $5.80121 \mathrm{E}-06$ & 2 & 2 & 2 & Up \\
\hline FCGR2A & Fc fragment of IgG, low affinity IIa, receptor (CD32) & $3.91836 \mathrm{E}-06$ & 3 & 3 & 1 & Up \\
\hline PRKAR2B & Protein kinase, cAMP-dependent, regulatory, type II, beta & 3.20593E-06 & 2 & 1 & 2 & Down \\
\hline SHC3 & $\begin{array}{l}\text { SHC (Src homology } 2 \text { domain containing) } \\
\text { transforming protein } 3\end{array}$ & 0 & 9 & 9 & 0 & Down \\
\hline SHC2 & $\begin{array}{l}\text { SHC (Src homology } 2 \text { domain containing) } \\
\text { transforming protein } 2\end{array}$ & 0 & 9 & 9 & 0 & Down \\
\hline HLA-DQA2 & Major histocompatibility complex, class II, DQ alpha 2 & 0 & 8 & 7 & 8 & Up \\
\hline HLA-DPA1 & Major histocompatibility complex, class II, DP alpha 1 & 0 & 8 & 7 & 8 & Up \\
\hline HLA-DRA & Major histocompatibility complex, class II, DR alpha & 0 & 8 & 7 & 8 & Up \\
\hline HLA-DPB 1 & Major histocompatibility complex, class II, DP beta 1 & 0 & 8 & 7 & 8 & Up \\
\hline HLA-DOA & Major histocompatibility complex, class II, DO alpha & 0 & 8 & 7 & 8 & Up \\
\hline HLA-DOB & Major histocompatibility complex, class II, DO beta & 0 & 8 & 7 & 8 & Up \\
\hline RXRG & Retinoid X receptor, gamma & 0 & 7 & 0 & 7 & Down \\
\hline FGR & Gardner-Rasheed feline sarcoma viral (v-fgr) oncogene homolog & 0 & 7 & 0 & 7 & Up \\
\hline GNG7 & Guanine nucleotide binding protein (G protein), gamma 7 & 0 & 6 & 0 & 6 & Down \\
\hline CXCL2 & Chemokine (C-X-C motif) ligand 2 & 0 & 6 & 0 & 6 & Up \\
\hline CCL4L1 & Chemokine (C-C motif) ligand 4-like 1 & 0 & 6 & 0 & 6 & $\mathrm{Up}$ \\
\hline CCL3 & Chemokine (C-C motif) ligand 3 & 0 & 6 & 0 & 6 & Up \\
\hline CCL2 & Chemokine (C-C motif) ligand 2 & 0 & 6 & 0 & 6 & Up \\
\hline CXCL14 & Chemokine (C-X-C motif) ligand 14 & 0 & 6 & 0 & 6 & Down \\
\hline CXCL16 & Chemokine (C-X-C motif) ligand 16 & 0 & 6 & 0 & 6 & Up \\
\hline WWP1 & WW domain containing E3 ubiquitin protein ligase 1 & 0 & 5 & 0 & 5 & Down \\
\hline CD74 & $\begin{array}{l}\text { CD74 molecule, major histocompatibility complex, } \\
\text { class II invariant chain }\end{array}$ & 0 & 5 & 5 & 0 & Up \\
\hline
\end{tabular}


Table VII. Continued.

\begin{tabular}{|c|c|c|c|c|c|c|}
\hline $\begin{array}{l}\text { Gene } \\
\text { symbol }\end{array}$ & Description & $\begin{array}{l}\text { Betweenness } \\
\text { centrality }\end{array}$ & Degree & Indegree & Outdegree & Style \\
\hline PGR & Progesterone receptor & 0 & 4 & 0 & 4 & Down \\
\hline PLA2G2A & Phospholipase A2, group IIA (platelets, synovial fluid) & 0 & 4 & 4 & 0 & Down \\
\hline FCER1G & $\begin{array}{l}\text { Fc fragment of IgE, high affinity I, receptor for; gamma } \\
\text { polypeptide }\end{array}$ & 0 & 4 & 3 & 3 & Up \\
\hline CCND2 & Cyclin D2 & 0 & 4 & 4 & 0 & Down \\
\hline PLA2G5 & Phospholipase A2, group V & 0 & 4 & 4 & 0 & Up \\
\hline RASSF5 & Ras association (RalGDS/AF-6) domain family member 5 & 0 & 4 & 0 & 4 & $\mathrm{Up}$ \\
\hline PDGFA & Platelet-derived growth factor alpha polypeptide & 0 & 4 & 0 & 4 & Up \\
\hline WNT5A & Wingless-type MMTV integration site family, member 5A & 0 & 4 & 2 & 2 & Down \\
\hline LIFR & Leukemia inhibitory factor receptor alpha & 0 & 3 & 2 & 1 & Down \\
\hline CD226 & CD226 molecule & 0 & 3 & 3 & 0 & Up \\
\hline LAMB3 & Laminin, beta 3 & 0 & 3 & 0 & 3 & Up \\
\hline SPP1 & Secreted phosphoprotein 1 & 0 & 3 & 0 & 3 & Up \\
\hline HGF & Hepatocyte growth factor (hepapoietin A; scatter factor) & 0 & 3 & 0 & 3 & Up \\
\hline LAMA2 & Laminin, alpha 2 & 0 & 3 & 0 & 3 & Down \\
\hline SFRP1 & Secreted frizzled-related protein 1 & 0 & 3 & 0 & 3 & Down \\
\hline SFRP2 & Secreted frizzled-related protein 2 & 0 & 3 & 0 & 3 & Down \\
\hline FGF9 & Fibroblast growth factor 9 (glia-activating factor) & 0 & 3 & 0 & 3 & Down \\
\hline IL13RA1 & Interleukin 13 receptor, alpha 1 & 0 & 3 & 2 & 1 & Up \\
\hline GHR & Growth hormone receptor & 0 & 3 & 2 & 1 & Down \\
\hline ICAM1 & Intercellular adhesion molecule 1 & 0 & 3 & 3 & 0 & Up \\
\hline IL6R & Interleukin 6 receptor & 0 & 3 & 2 & 1 & Up \\
\hline IL7R & Interleukin 7 receptor & 0 & 3 & 2 & 1 & Up \\
\hline AMPH & Amphiphysin & 0 & 3 & 3 & 0 & Down \\
\hline COL6A6 & Collagen, type VI, alpha 6 & 0 & 3 & 0 & 3 & Down \\
\hline IL10RB & Interleukin 10 receptor, beta & 0 & 3 & 2 & 1 & Up \\
\hline THBS1 & Thrombospondin 1 & 0 & 3 & 0 & 3 & Up \\
\hline THBS2 & Thrombospondin 2 & 0 & 3 & 0 & 3 & Up \\
\hline THBS4 & Thrombospondin 4 & 0 & 3 & 0 & 3 & Down \\
\hline FGF10 & Fibroblast growth factor 10 & 0 & 3 & 0 & 3 & Down \\
\hline TGFB1 & Transforming growth factor, beta 1 & 0 & 3 & 3 & 0 & Up \\
\hline FGF20 & Fibroblast growth factor 20 & 0 & 3 & 0 & 3 & Up \\
\hline IL11RA & Interleukin 11 receptor, alpha & 0 & 3 & 2 & 1 & Down \\
\hline HCST & Hematopoietic cell signal transducer & 0 & 3 & 0 & 3 & Up \\
\hline RELN & Reelin & 0 & 3 & 0 & 3 & Down \\
\hline COL1A1 & Collagen, type I, alpha 1 & 0 & 3 & 0 & 3 & Up \\
\hline CNTFR & Ciliary neurotrophic factor receptor & 0 & 3 & 2 & 1 & Down \\
\hline DOCK2 & Dedicator of cytokinesis 2 & 0 & 3 & 3 & 0 & $\mathrm{Up}$ \\
\hline IL12RB1 & Interleukin 12 receptor, beta 1 & 0 & 3 & 2 & 1 & Up \\
\hline ICOS & Inducible T-cell co-stimulator & 0 & 3 & 0 & 3 & Up \\
\hline MYLK & Myosin light chain kinase & 0 & 3 & 3 & 0 & Down \\
\hline IL21R & Interleukin 21 receptor & 0 & 3 & 2 & 1 & Up \\
\hline PAK7 & p21 protein $(\mathrm{Cdc} 42 / \mathrm{Rac})$-activated kinase 7 & 0 & 3 & 0 & 3 & Down \\
\hline PAK3 & p21 protein $(\mathrm{Cdc} 42 / \mathrm{Rac})$-activated kinase 3 & 0 & 3 & 0 & 3 & Down \\
\hline IL2RG & Interleukin 2 receptor, gamma & 0 & 3 & 2 & 1 & Up \\
\hline PTPRC & Protein tyrosine phosphatase, receptor type, C & 0 & 3 & 0 & 3 & Up \\
\hline IL2RB & Interleukin 2 receptor, beta & 0 & 3 & 2 & 1 & Up \\
\hline
\end{tabular}


Table VII. Continued.

\begin{tabular}{|c|c|c|c|c|c|c|}
\hline $\begin{array}{l}\text { Gene } \\
\text { symbol }\end{array}$ & Description & $\begin{array}{l}\text { Betweenness } \\
\text { centrality }\end{array}$ & Degree & Indegree & Outdegree & Style \\
\hline TNXB & Tenascin XB & 0 & 3 & 0 & 3 & Down \\
\hline IL2RA & Interleukin 2 receptor, alpha & 0 & 3 & 2 & 1 & Up \\
\hline COL4A6 & Collagen, type IV, alpha 6 & 0 & 3 & 0 & 3 & Down \\
\hline BTC & Betacellulin & 0 & 2 & 0 & 2 & Down \\
\hline FAS & Fas (TNF receptor superfamily, member 6) & 0 & 2 & 2 & 0 & Up \\
\hline PTPRF & Protein tyrosine phosphatase, receptor type, F & 0 & 2 & 0 & 2 & Down \\
\hline PIM1 & Pim-1 oncogene & 0 & 2 & 2 & 0 & Up \\
\hline GNAZ & $\begin{array}{l}\text { Guanine nucleotide binding protein ( } \mathrm{G} \text { protein), } \\
\text { alpha z polypeptide }\end{array}$ & 0 & 2 & 0 & 2 & Down \\
\hline KCNMA1 & $\begin{array}{l}\text { Potassium large conductance calcium-activated channel, } \\
\text { subfamily } \mathrm{M} \text {, alpha member } 1\end{array}$ & 0 & 2 & 2 & 0 & Down \\
\hline GZMA & $\begin{array}{l}\text { Granzyme A (granzyme 1, cytotoxic T-lymphocyte-associated } \\
\text { serine esterase } 3 \text { ) }\end{array}$ & 0 & 2 & 0 & 2 & Up \\
\hline ARHGEF6 & Rac/Cdc42 guanine nucleotide exchange factor (GEF) 6 & 0 & 2 & 2 & 0 & Up \\
\hline ICAM3 & Intercellular adhesion molecule 3 & 0 & 2 & 0 & 2 & Up \\
\hline MMP14 & Matrix metallopeptidase 14 (membrane-inserted) & 0 & 2 & 2 & 0 & Up \\
\hline RUNX1 & Runt-related transcription factor 1 & 0 & 2 & 1 & 2 & Up \\
\hline LIMK1 & LIM domain kinase 1 & 0 & 2 & 2 & 0 & Up \\
\hline LIPE & Lipase, hormone-sensitive & 0 & 2 & 2 & 0 & Down \\
\hline PTGS2 & $\begin{array}{l}\text { Prostaglandin-endoperoxide synthase } 2 \text { (prostaglandin G/H } \\
\text { synthase and cyclooxygenase) }\end{array}$ & 0 & 1 & 1 & 0 & Up \\
\hline ADCY5 & Adenylate cyclase 5 & 0 & 1 & 0 & 1 & Down \\
\hline FST & Follistatin & 0 & 1 & 0 & 1 & Up \\
\hline LHCGR & Luteinizing hormone/choriogonadotropin receptor & 0 & 1 & 0 & 1 & Down \\
\hline PRKG1 & Protein kinase, cGMP-dependent, type I & 0 & 1 & 0 & 1 & Down \\
\hline AGTR1 & Angiotensin II receptor, type 1 & 0 & 1 & 0 & 1 & Down \\
\hline PPP1R1A & Protein phosphatase 1 , regulatory (inhibitor) subunit $1 \mathrm{~A}$ & 0 & 1 & 1 & 0 & Down \\
\hline MAP2K6 & Mitogen-activated protein kinase kinase 6 & 0 & 1 & 0 & 1 & Down \\
\hline LILRB3 & $\begin{array}{l}\text { Leukocyte immunoglobulin-like receptor, subfamily B } \\
\text { (with TM and ITIM domains), member } 3\end{array}$ & 0 & 1 & 1 & 1 & Up \\
\hline GRAP2 & GRB2-related adaptor protein 2 & 0 & 1 & 1 & 1 & Up \\
\hline DUSP10 & Dual specificity phosphatase 10 & 0 & 1 & 0 & 1 & Up \\
\hline CD72 & CD72 molecule & 0 & 1 & 1 & 1 & Up \\
\hline CTSL1 & Cathepsin L1 & 0 & 1 & 0 & 1 & Up \\
\hline AVPR1A & Arginine vasopressin receptor $1 \mathrm{~A}$ & 0 & 1 & 0 & 1 & Down \\
\hline AREG & Amphiregulin & 0 & 1 & 0 & 1 & Up \\
\hline WAS & Wiskott-Aldrich syndrome (eczema-thrombocytopenia) & 0 & 1 & 1 & 0 & Up \\
\hline CARD11 & Caspase recruitment domain family, member 11 & 0 & 1 & 1 & 0 & Up \\
\hline DAPP1 & Dual adaptor of phosphotyrosine and 3-phosphoinositides & 0 & 1 & 1 & 0 & Up \\
\hline PLIN1 & Perilipin 1 & 0 & 1 & 1 & 0 & Down \\
\hline GRIA3 & Glutamate receptor, ionotrophic, AMPA 3 & 0 & 1 & 0 & 1 & Down \\
\hline RPS6KA6 & Ribosomal protein S6 kinase, 90kDa, polypeptide 6 & 0 & 1 & 1 & 0 & Down \\
\hline DUSP2 & Dual specificity phosphatase 2 & 0 & 1 & 0 & 1 & Up \\
\hline RPS6KA1 & Ribosomal protein S6 kinase, 90kDa, polypeptide 1 & 0 & 1 & 1 & 0 & Up \\
\hline ARNT2 & Aryl-hydrocarbon receptor nuclear translocator 2 & 0 & 1 & 1 & 1 & Down \\
\hline CDKN2B & Cyclin-dependent kinase inhibitor 2B (p15, inhibits CDK4) & 0 & 1 & 0 & 1 & Up \\
\hline CDKN2C & Cyclin-dependent kinase inhibitor $2 \mathrm{C}$ (p18, inhibits CDK4) & 0 & 1 & 0 & 1 & Up \\
\hline
\end{tabular}


Table VII. Continued.

\begin{tabular}{|c|c|c|c|c|c|c|}
\hline $\begin{array}{l}\text { Gene } \\
\text { symbol }\end{array}$ & Description & $\begin{array}{l}\text { Betweenness } \\
\text { centrality }\end{array}$ & Degree & Indegree & Outdegree & Style \\
\hline MS4A2 & $\begin{array}{l}\text { Membrane-spanning 4-domains, subfamily A, member } 2 \text { ( } \mathrm{Fc} \\
\text { fragment of IgE, high affinity I, receptor for; beta polypeptide) }\end{array}$ & 0 & 1 & 1 & 0 & Up \\
\hline HLA-E & Major histocompatibility complex, class I, E & 0 & 1 & 0 & 1 & Up \\
\hline CYSLTR2 & Cysteinyl leukotriene receptor 2 & 0 & 1 & 0 & 1 & Up \\
\hline ANGPTL4 & Angiopoietin-like 4 & 0 & 1 & 1 & 0 & Up \\
\hline FABP4 & Fatty acid binding protein 4 , adipocyte & 0 & 1 & 1 & 0 & Down \\
\hline CD79A & CD79a molecule, immunoglobulin-associated alpha & 0 & 1 & 1 & 0 & Up \\
\hline ADRA1D & Adrenergic, alpha-1D-, receptor & 0 & 1 & 0 & 1 & Down \\
\hline TACR1 & Tachykinin receptor 1 & 0 & 1 & 0 & 1 & Down \\
\hline GSN & Gelsolin & 0 & 1 & 1 & 0 & Down \\
\hline EGR1 & Early growth response 1 & 0 & 1 & 0 & 1 & Up \\
\hline CTSS & Cathepsin S & 0 & 1 & 0 & 1 & Up \\
\hline ACADL & Acyl-CoA dehydrogenase, long chain & 0 & 1 & 1 & 0 & Down \\
\hline CD86 & CD86 molecule & 0 & 1 & 0 & 1 & Up \\
\hline CD80 & CD80 molecule & 0 & 1 & 1 & 0 & Up \\
\hline CTSB & Cathepsin B & 0 & 1 & 0 & 1 & Up \\
\hline OXTR & Oxytocin receptor & 0 & 1 & 0 & 1 & Up \\
\hline $\mathrm{DCN}$ & Decorin & 0 & 1 & 0 & 1 & Down \\
\hline TNFRSF1B & Tumor necrosis factor receptor superfamily, member 1B & 0 & 1 & 1 & 0 & Up \\
\hline OLR1 & Oxidized low density lipoprotein (lectin-like) receptor 1 & 0 & 1 & 1 & 0 & Up \\
\hline OR51E2 & Olfactory receptor, family 51 , subfamily E, member 2 & 0 & 1 & 1 & 0 & Up \\
\hline ADIPOQ & Adiponectin, $\mathrm{C} 1 \mathrm{Q}$ and collagen domain containing & 0 & 1 & 1 & 0 & Down \\
\hline IGFBP3 & Insulin-like growth factor binding protein 3 & 0 & 1 & 0 & 1 & Up \\
\hline
\end{tabular}

$\mathrm{GO}$ is widely recognized as the premier tool for the organization and functional annotation of molecular aspects (41). GO analysis was used to interpret each GO of the differentially expressed genes and analyze it statistically. By using the criteria of $\mathrm{P}<0.05$, significant $\mathrm{GO}$ items and genes involved were identified. Guo et al used GO analysis to analyze miRNA microarrays and found that miR-15b and miR-16 may be indispensable for apoptosis by targeting Bcl-2 (42). GO terms regarding inflammatory response play an important role in CTEPH; a number of studies have reported CRP as a predictor of adverse outcome in pulmonary arterial hypertension (43), and IL-6-mediated systemic inflammatory cascades may also be involved in the regulation of peripheral vascular tone following pulmonary thromboendarterectomy (PTE) (44). Quarck et al reported that a proliferative phenotype of pulmonary arterial smooth muscle cells and endothelial cells contributed to proximal vascular remodeling in CTEPH (45). A number of studies have proven that patients with CTEPH can generate a pronounced inflammatory response with the release of pro-inflammatory and anti-inflammatory cytokines $(44,46)$. Therefore, we hypothesized that the functions of other items listed may play a role in CTEPH, which has not been elucidated yet.
GO analysis is a classical method used to annotate gene function but is still inexact in some fields. Pathway analysis can reveal the distinct biological process and identify significant pathways that differentially expressed genes participate in; based on this, we can have a comprehensive understanding as to the interactions of genes, functions that they participate in and associations between up- and down-stream pathways, and identify genes involved in these significant pathways. The concordance of the MAPK signaling pathway, cytokinecytokine receptor interaction and apoptosis with the GO terms confirmed their critical role in CTEPH. Wei et al demonstrated that JNK is a critical molecule in 5-HT-induced pulmonary artery smooth muscle cell (PASMC) proliferation and migration and may act at an important point for crosstalk of the MAPK and phosphoinositide 3-kinase (PI3K) pathways (47); however, to our knowledge, there is no study available on the role of the MAPK signaling pathway in CTEPH. Numerous studies have proven that focal adhesion and cytokine participate in the process of vascular remodeling, which is an important characteristic of CTEPH $(48,49)$. A previous study on the role of CRP in proximal pulmonary endothelial cells and smooth muscle cells also demonstrated the effects of cell adhesion molecules on CTEPH (5). Since CTEPH is still a rare disease 
worldwide, information on the signaling pathways associated with its development is limited. We hypothesized that the other seemingly irrelevant pathways may play a role in CTEPH. However, this requires further investigation. Pathway analysis revealed equally important roles and functions as GO analysis.

In the investigation of genes involved in significant GO terms and pathways, 232 genes in common were found that may affect the development of CTEPH. JAK3 is an enzyme in the janus kinase family and has been implicated in cell signaling processes important in cancer and immune-inflammatory diseases (50). Recently, it was found to improve myocardial vascular permeability (51); however, its role in CTEPH remains unelucidated. The functions of GNA15 and ARRB2 have been less frequently reported. MAPK13 mainly participates in cholangiocarcinoma and increases cell migration; it may play a similar role in CTEPH (52). F2R, also known as PAR-1, affects vascular remodeling in the small intestine (53). Vascular cell adhesion molecule 1 (VCAM1) has been reported to modulate blood vessel endothelial cell-leukocyte interactions and increase the strength of cell adhesion (54). Although their functions have not been fully investigated, a number of genes may play a role in the development of CTEPH. Based on these data, further studies on the expression of these genes and protein functions are required using a greater sample number and using methods, such as reverse transcriptase-polymerase chain reaction and western blot analysis; moreover, the regulatory functions of the identified genes and proteins also requires investigation. Further studies may help to improve the clinical diagnosis and treatment of patients with CTEPH.

In conlcusion, the results presented in our study suggest that differences in gene expression exist between CTEPH and normal samples. These genes encode proteins involved in different GO items and signaling pathways, the disruption of which can affect the development of CTEPH. Several genes, such as JAK3, GNA15, MAPK13, F2R and VCAM1 provide potential candidates for distinguishing between CTEPH from healthy individuals in the future. This distinction may aid in the diagnosis and prevention of CTEPH, based on the different features.

\section{Acknowledgements}

This study was supported by the High-Level Technic Personnel Training Plan of Beijing Health System (no. 2011-3-017).

\section{References}

1. Hoeper MM, Mayer E, Simonneau G and Rubin LJ: Chronic thromboembolic pulmonary hypertension. Circulation 113 2011-2020, 2006.

2. Mayer E and Klepetko W: Techniques and outcomes of pulmonary endarterectomy for chronic thromboembolic pulmonary hypertension. Proc Am Thorac Soc 3: 589-593, 2006.

3. Freed DH, Thomson BM, Tsui SS, et al: Functional and haemodynamic outcome 1 year after pulmonary thromboendarterectomy. Eur J Cardiothorac Surg 34: 525-530, 2008.

4. Bonderman D, Jakowitsch J, Redwan B, et al: Role for staphylococci in misguided thrombus resolution of chronic thromboembolic pulmonary hypertension. Arterioscler Thromb Vasc Biol 28: 678-684, 2008

5. Wynants M, Quarck R, Ronisz A, et al: Effects of C-reactive protein on human pulmonary vascular cells in chronic thromboembolic pulmonary hypertension. Eur Respir J 40: 886-894, 2012.
6. Lang IM and Klepetko W: Chronic thromboembolic pulmonary hypertension: an updated review. Curr Opin Cardiol 23: 555-559, 2008.

7. Wolf M, Boyer-Neumann C, Parent F, et al: Thrombotic risk factors in pulmonary hypertension. Eur Respir J 15: 395-399, 2000.

8. Dartevelle P, Fadel E, Mussot S, et al: Chronic thromboembolic pulmonary hypertension. Eur Respir J 23: 637-648, 2004.

9. Devaraj S, Singh U and Jialal I: The evolving role of C-reactive protein in atherothrombosis. Clin Chem 55: 229-238, 2009.

10. Barton M and Yanagisawa M: Endothelin: 20 years from discovery to therapy. Can J Physiol Pharmacol 86: 485-498, 2008.

11. Hoeper MM, Barbera JA, Channick RN, et al: Diagnosis, assessment, and treatment of non-pulmonary arterial hypertension pulmonary hypertension. J Am Coll Cardiol 54: S85-S96, 2009.

12. Badesch DB, Champion HC, Sanchez MA, et al: Diagnosis and assessment of pulmonary arterial hypertension. J Am Coll Cardiol 54: S55-S66, 2009.

13. Auger WR, Fedullo PF, Moser KM, Buchbinder M and Peterson KL: Chronic major-vessel thromboembolic pulmonary artery obstruction: appearance at angiography. Radiology 182: 393-398, 1992

14. Wright GW and Simon RM: A random variance model for detection of differential gene expression in small microarray experiments. Bioinformatics 19: 2448-2455, 2003.

15. Yang H, Crawford N, Lukes L, Finney R, Lancaster M and Hunter KW: Metastasis predictive signature profiles pre-exist in normal tissues. Clin Exp Metastasis 22: 593-603, 2005.

16. Clarke R, Ressom HW, Wang A, et al: The properties of highdimensional data spaces: implications for exploring gene and protein expression data. Nat Rev Cancer 8: 37-49, 2008.

17. The Gene Ontology (GO) project in 2006. Nucleic Acids Res 34: D322-D326, 2006.

18. Ashburner M, Ball CA, Blake JA, et al: Gene ontology: tool for the unification of biology. The Gene Ontology Consortium. Nat Genet 25: 25-29, 2000.

19. Dupuy D, Bertin N, Hidalgo CA, et al: Genome-scale analysis of in vivo spatiotemporal promoter activity in Caenorhabditis elegans. Nat Biotechnol 25: 663-668, 2007.

20. Schlitt T, Palin K, Rung J, et al: From gene networks to gene function. Genome Res 13: 2568-2576, 2003.

21. Kanehisa M, Goto S, Kawashima S, Okuno Y and Hattori M: The KEGG resource for deciphering the genome. Nucleic Acids Res 32: D277-D280, 2004.

22. Yi M, Horton JD, Cohen JC, Hobbs HH and Stephens RM: WholePathwayScope: a comprehensive pathway-based analysis tool for high-throughput data. BMC Bioinformatics 7: 30, 2006.

23. Draghici S, Khatri P, Tarca AL, et al: A systems biology approach for pathway level analysis. Genome Res 17: 1537-1545, 2007.

24. Jansen R, Greenbaum D and Gerstein M: Relating whole-genome expression data with protein-protein interactions. Genome Res 12: $37-46,2002$

25. Li C and Li H: Network-constrained regularization and variable selection for analysis of genomic data. Bioinformatics 24: 1175-1182, 2008.

26. Wei $\mathrm{Z}$ and Li H: A Markov random field model for networkbased analysis of genomic data. Bioinformatics 23: 1537-1544, 2007.

27. Zhang JD and Wiemann S: KEGGgraph: a graph approach to KEGG PATHWAY in R and bioconductor. Bioinformatics 25: 1470-1471, 2009.

28. Spirin V and Mirny LA: Protein complexes and functional modules in molecular networks. Proc Natl Acad Sci USA 100: 12123-12128, 2003

29. Pepke-Zaba J, Delcroix M, Lang I, et al: Chronic thromboembolic pulmonary hypertension (CTEPH): results from an international prospective registry. Circulation 124: 1973-1981, 2011.

30. Bonderman D, Turecek PL, Jakowitsch J, et al: High prevalence of elevated clotting factor VIII in chronic thromboembolic pulmonary hypertension. Thromb Haemost 90: 372-376, 2003.

31. Lang IM, Marsh JJ, Olman MA, Moser KM and Schleef RR: Parallel analysis of tissue-type plasminogen activator and type 1 plasminogen activator inhibitor in plasma and endothelial cells derived from patients with chronic pulmonary thromboemboli. Circulation 90: 706-712, 1994.

32. Morris TA, Marsh JJ, Chiles PG, et al: High prevalence of dysfibrinogenemia among patients with chronic thromboembolic pulmonary hypertension. Blood 114: 1929-1936, 2009. 
33. Suntharalingam J, Goldsmith K, van Marion V, et al: Fibrinogen Aalpha Thr312Ala polymorphism is associated with chronic thromboembolic pulmonary hypertension. Eur Respir J 31: 736-741, 2008.

34. Bonderman D, Wilkens H, Wakounig S, et al: Risk factors for chronic thromboembolic pulmonary hypertension. Eur Respir J 33: 325-331, 2009.

35. Chen $X$ and Wang L: Integrating biological knowledge with gene expression profiles for survival prediction of cancer. J Comput Biol 16: 265-278, 2009.

36. Gu Y, Liu Z, Li L, et al: OLR1, PON1 and MTHFR gene polymorphisms, conventional risk factors and the severity of coronary atherosclerosis in a Chinese Han population. Cell Physiol Biochem 31: 143-152, 2013.

37. Lindner J, Maruna P, Kunstyr J, et al: Hemodynamic instability after pulmonary endarterectomy for chronic thromboembolic pulmonary hypertension correlates with cytokine network hyperstimulation. Eur Surg Res 43: 39-46, 2009.

38. Zeng J, Yang X, Cheng L, et al: Chemokine CXCL14 is associated with prognosis in patients with colorectal carcinoma after curative resection. J Transl Med 11: 6, 2013.

39. Gu XL, Ou ZL, Lin FJ, et al: Expression of CXCL14 and its anticancer role in breast cancer. Breast Cancer Res Treat 135 725-735, 2012.

40. Mahmood S, Beetz C, Tahir MM, et al: First HPSE2 missense mutation in urofacial syndrome. Clin Genet 81: 88-92, 2012.

41. Lovering RC, Camon EB, Blake JA and Diehl AD: Access to immunology through the Gene Ontology. Immunology 125 154-160, 2008

42. Guo CJ, Pan Q, Li DG, Sun H and Liu BW: miR-15b and miR-16 are implicated in activation of the rat hepatic stellate cell: an essential role for apoptosis. J Hepatol 50: 766-778, 2009.

43. Quarck R, Nawrot T, Meyns B and Delcroix M: C-reactive protein: a new predictor of adverse outcome in pulmonary arterial hypertension. J Am Coll Cardiol 53: 1211-1218, 2009.

44. Langer F, Schramm R, Bauer M, Tscholl D, Kunihara T and Schafers HJ: Cytokine response to pulmonary thromboendarterectomy. Chest 126: 135-141, 2004.
45. Quarck R, Wynants M, Ronisz A, et al: Characterization of proximal pulmonary arterial cells from chronic thromboembolic pulmonary hypertension patients. Respir Res 13: 27, 2012.

46. Von Haehling S, von Bardeleben RS, Kramm T, et al: Inflammation in right ventricular dysfunction due to thromboembolic pulmonary hypertension. Int J Cardiol 144: 206-211, 2010.

47. Wei L, Liu Y, Kaneto H and Fanburg BL: JNK regulates serotonin-mediated proliferation and migration of pulmonary artery smooth muscle cells. Am J Physiol Lung Cell Mol Physiol 298: L863-L869, 2010.

48. Stone JD, Narine A, Shaver PR, Fox JC, Vuncannon JR and Tulis DA: AMP-activated protein kinase inhibits vascular smooth muscle cell proliferation and migration and vascular remodeling following injury. Am J Physiol Heart Circ Physiol 304: H369-H381, 2013.

49. Farkas L, Gauldie J, Voelkel NF and Kolb M: Pulmonary hypertension and idiopathic pulmonary fibrosis: a tale of angiogenesis, apoptosis, and growth factors. Am J Respir Cell Mol Biol 45: 1-15, 2011.

50. Sun Z, Luo Q, Ye D, Chen W and Chen F: Role of toll-like receptor 4 on the immune escape of human oral squamous cell carcinoma and resistance of cisplatin-induced apoptosis. Mol Cancer 11: 33, 2012.

51. Lee JE, Lee AS, Kim DH, et al: Janex-1, a JAK3 inhibitor, ameliorates tumor necrosis factor-alpha-induced expression of cell adhesion molecules and improves myocardial vascular permeability in endotoxemic mice. Int J Mol Med 29: 864-870, 2012.

52. Tan FL, Ooi A, Huang D, et al: p38delta/MAPK13 as a diagnostic marker for cholangiocarcinoma and its involvement in cell motility and invasion. Int J Cancer 126: 2353-2361, 2010.

53. Reinhardt C, Bergentall M, Greiner TU, et al: Tissue factor and PAR1 promote microbiota-induced intestinal vascular remodelling. Nature 483: 627-631, 2012.

54. Rafat M, Rotenstein LS, Hu JL and Auguste DT: Engineered endothelial cell adhesion via VCAM1 and E-selectin antibodypresenting alginate hydrogels. Acta Biomater 8: 2697-2703, 2012. 